Title:

\title{
Annoyance, detection and recognition of wind turbine noise
}

Authors:

Timothy [Van Renterghem] $]^{\mathrm{a}}$, Annelies Bockstael ${ }^{\mathrm{a}}$, Valentine [De Weirt] ${ }^{\mathrm{a}}$, Dick Botteldooren $^{\mathrm{a}}$

Affiliation:

${ }^{a}$ Ghent University,

Department of Information Technology,

Sint-Pietersnieuwstraat 41,

B- 9000 Gent,

Belgium.

Corresponding author:

Timothy Van Renterghem

Timothy.Van.Renterghem@intec.Ugent.be

TEL : +32 92643634

FAX : +3292649969 


\begin{abstract}
Annoyance, recognition and detection of noise from a single wind turbine was studied by means of a two-stage listening experiment with 50 participants with normal hearing abilities. In-situ recordings made at close distance from a 1.8-MW wind turbine operating at $22 \mathrm{rpm}$ were mixed with road traffic noise, and processed to simulate indoor sound pressure levels at $L_{\text {Aeq }} 40 \mathrm{dBA}$. In a first part, where people were unaware of the true purpose of the experiment, samples were played during a quiet leisure activity. Under these conditions, pure wind turbine noise gave very similar annoyance ratings as unmixed highway noise at the same equivalent level, while annoyance by local road traffic noise was significantly higher. In a second experiment, listeners were asked to identify the sample containing wind turbine noise in a paired comparison test. The detection limit of wind turbine noise in presence of highway noise was estimated to be as low as a signal-to-noise ratio of - $23 \mathrm{dBA}$. When mixed with local road traffic, such a detection limit could not be determined. These findings support that noticing the sound could be an important aspect of wind turbine noise annoyance at the low equivalent levels typically observed indoors in practice. Participants that easily recognized wind-turbine(-like) sounds could detect wind turbine noise better when submersed in road traffic noise. Recognition of wind turbine sounds is also linked to higher annoyance. Awareness of the source is therefore a relevant aspect of wind turbine noise perception which is consistent with previous research.
\end{abstract}

keywords : noise annoyance; wind turbine noise; listening test; sound detection; sound recognition 


\section{Introduction}

Noise annoyance caused by wind turbines has become an emerging problem in recent years, due to the rapid increase in number of wind turbines, triggered by sustainable energy goals set forward at the national and international level. Up to now, not all aspects of the generation, propagation and perception of wind turbine noise are well understood. Researchers found that in case of equal day-evening-night equivalent levels $\left(L_{\text {den }}\right)$ at the facades of dwellings, the annoyance caused by wind turbines is systematically higher than caused by other environmental noise sources like road traffic noise or railway noise (Janssen et al., 2011; Pedersen and Persson-Waye, 2004; Pedersen et al., 2009). Complex sound generation, propagation and perception related effects that are expected to play a role are the directivity and periodicity of the noise (Bockstael et al., 2012), amplitude modulations (Moorhouse et al., 2007; Lee et al., 2011), the low-frequency content (Salt and Hullar, 2010; Bolin et al., 2011; Møller and Pedersen, 2011), tonal noise (Hubbard and Shepherd, 1991), impulsive noises in strong turbulence (van den Berg, 2004), "swishing/lashing" sounds (Palmer, 2009; Pedersen et al., 2009), the visual setting (Janssen et al., 2011; Pedersen and Larsman, 2008; Pedersen and Persson-Waye, 2004; Pedersen and Persson-Waye, 2007), the general attitude towards wind turbines (Pedersen and Persson-Waye, 2007; Pedersen et al., 2009; Pedersen et al., 2010) and the presence of economic benefits (Janssen et al., 2011; Pedersen et al., 2009).

Masking of wind turbine noise with other sounds could potentially reduce negative effects in some situations. In general, the impact of wind turbine noise on annoyance, self-reported sleep disturbance, and psychological distress was found to be stronger for people living in quieter areas, so with less background noise (Bakker et al., 2012). Masking of wind turbine noise has been studied mainly for natural sounds and road traffic noise. 
Masking of wind turbine noise by wind-induced vegetation noise and airborne sea noise has been investigated by Bolin et al. (2010) and Fégeant (2002). With increasing wind speed, wind turbines emit more noise, but also wind-induced vegetation noise levels are proportional to the wind speed (Bolin, 2009; Fégeant, 1999). In addition, this type of noise has a broad frequency spectrum and is of natural origin, and therefore a good candidate to mask wind turbine noise. Bolin found in his controlled listening experiment that masking occurs at a signal-to-noise ratio (SNR) of wind turbine noise, relative to such natural sounds, near -10 dBA.

In many European countries, road traffic is a widespread noise source. Although road traffic noise is also a major source of noise annoyance, in general, the annoyance seems to be lower than for wind turbines (Janssen et al., 2011). In addition, highways are usually located in open terrain, making these locations often suited for placing wind turbines. There are also similarities as regards the frequency spectrum of both noise sources (Pedersen et al., 2010). In Pedersen et al. (2010), an annoyance survey was linked to calculated sound pressure levels. The main conclusion from this research is that road traffic noise did not in general decrease annoyance by wind turbine noise, except when levels of predicted wind turbine noise were low (35-40 dBA $\left.L_{d e n}\right)$ and in case of a SNR below -20 dBA (Pedersen et al., 2010).

The current study extends this previous work on combined exposure to wind turbine and road traffic noise in several ways under controlled conditions by means of listening tests. The research by Pedersen et al. (2010) is based on calculated sound pressure levels near wind turbines and road traffic sources. However, accurate predictions are difficult, especially since the state of the atmosphere plays an important role on both the generation (wind turbines) and propagation (both road traffic and wind turbines) of sound. This is enhanced since wind turbine noise will be mainly relevant during windy periods. The latter effects are not sufficiently captured by model approaches that are able to cover a large area (as e.g. ISO9613-2). . In the current study, the distinction is also made between highway noise and local road traffic noise. The 
temporal structure of both types of traffic is clearly different, ranging from continuous to intermittent and dynamic, influencing the human perception. The $L_{\text {den }}$ noise indicator averaged over long periods does not give information on such dynamics. Finally, this study goes beyond previous work in explaining the mechanisms leading to reported noise annoyance.

The test in this study contained different parts. Firstly, an experiment during a quiet leisure activity in a living room was conducted to assess annoyance by wind turbine noise at different SNRs relative to road traffic noise (highway, local road). The participants were not aware of the true purpose of the experiment during this non-focused test. At the end of this part of the experiment, the participants were asked what sounds they thought to have heard. Secondly, people were asked to detect wind turbine noise, by comparing samples containing wind turbine noise to samples not containing wind turbine noise. The main goal of this focused listening task with headphones is finding detection limits of wind turbine noise submersed in road traffic noise samples. Next, a small questionnaire was completed querying about the opinion of the participants relative to renewable energy, previous experience with wind turbine noise, and their self-reported noise sensitivity. Finally, an audiometric test was conducted to be able to exclude abnormal hearing participants.

This paper is organized as follows. In a first part, the recording and processing of the audio samples is discussed. Next, both listening experiments are described in detail, including the setup of the test environments and the procedures followed. A next section deals with the test panel. The hearing status test and the survey are briefly described, and an overview is given of the characteristics of the test panel in the current experiment. In a following section, results are presented for the non-focused and focused listening test, and the answers to the sound recognition test are summarized. In a next section, the results of the different tests are combined in order to explore underlying mechanisms with relation to the perception of wind turbine noise. Finally, some conclusions are drawn. 


\section{Stimuli}

\subsection{Recording}

In-situ recordings of wind turbine noise were made at close distance from a wind turbine (see Fig. 1), with a (maximum) power of $1800 \mathrm{~kW}$. The height of the tower was $85 \mathrm{~m}$, and the length of the blades $35 \mathrm{~m}$. The wind turbine was a direct shaft type. It was properly functioning during recording.

During the recordings, the maximum allowed blade velocity during normal operation was reached (22 rotations per minute). The wind speed measured at a height of $85 \mathrm{~m}$ was 10-12 $\mathrm{m} / \mathrm{s}$. The air temperature at ground level was 8 degrees Celsius, under a cloudy sky. Measurements were performed at $30 \mathrm{~m}$ downwind from the tower, aligned with the wind direction, at a single spot. At the moment of the measurement, the wind turbine noise was the dominant part of the soundscape. Although wind turbine noise characteristics in the far-field could be different from those in the near-field, recordings at close distance is the only practical way to have undisturbed noise samples needed in the current listening experiment.

Recordings were made with a free-field 1/2" electret microphone MK250 (Microtech Gefell). This microphone capsule has a flat frequency response over the full audible frequency range, with deviations lower than $1 \mathrm{~dB}$ up to $15 \mathrm{kHz}$ for normal incident sound. The microphone capsule was connected to a pre-amplifier (SV 12, Svantek). The combination of the microphone capsule, pre-amplifier and logging unit (SVAN959, Svantek) is certified as class 1 equipment. An outdoor protection unit WME 952 (Microtech Gefell) was used, including a windscreen. To minimize wind-induced microphone noise, the microphone was positioned in a small holder above asphalt-covered ground (centre of microphone membrane at a height of about $5 \mathrm{~cm}$ ). The microphone was directed towards the tower of the wind turbine. The measurement chain was 
calibrated with a 1-kHz $94 \mathrm{~dB}$ (SV30A, Svantek, type 1) pistonphone before the recordings were started. The recordings were made at a sample frequency of $48 \mathrm{kHz}$, and a bit depth of 16 . Several monaural recordings were made and finally 7.5 minutes of undisturbed, continuous wind turbine noise was selected.

\section{[FIGURE 1]}

Samples of both highway noise and local road traffic noise were recorded. The first type was recorded at a distance of $50 \mathrm{~m}$ normal to a highway, for the second type the distance was $15 \mathrm{~m}$ from the road edge. The recorded highway noise was continuous, and individual passages could not be identified. As for the local road noise samples, individual car passages could be easily heard as traffic intensity was limited. Distinct periods of lower sound pressure level were present. Both light and heavy vehicles could be identified. At the moment of the recordings, the road traffic noise was the dominant part of the soundscape in both recordings, and no other noise sources could be heard. The temporal and spectral characteristics of the different types of road traffic noise is provided further in this paper.

\subsection{Processing}

This study deals with the perception of combined sound exposure indoors. The recordings of traffic noise and wind turbine noise were made at close distance to obtain undisturbed samples, however, direct use of these would lead to unrealistic distances to a typical dwelling. Outdoor sound propagation will affect the frequency balance, and in turn, the perception. In addition, transmission of sound through a closed window has to be accounted for as well, which is strongly frequency dependent.

To make the recordings more realistic for indoor noise exposure, the following strategy was followed. Both the wind turbine and highway were assumed to be at $250 \mathrm{~m}$ from the facade. The 
local road was positioned much closer, at $15 \mathrm{~m}$ from the facade, which is equal to the actual measured distance. As a result, the temporal structure, that might especially be important for the perception of local road noise, is well captured. Of main interest is the relative importance of high and low frequencies. Geometrical spreading does not alter the frequency balance when assuming point source propagation. The additional atmospheric absorption during propagation from the location of the wind turbine noise and the highway was added according to ISO9613-1. For the latter, the air temperature outdoors was considered to be 15 degrees Celsius, the relative humidity $70 \%$, and the atmospheric pressure $101325 \mathrm{~Pa}$.

Sound transmission through the window was accounted for in detail. Based on measurements reported by Quirt (1983), values for double 3-mm thick glazing were used, with an interpane spacing of $3 \mathrm{~mm}$. Below $500 \mathrm{~Hz}$, transmission loss is rather flat. Above $500 \mathrm{~Hz}$, a strong increase in transmission loss $(+15 \mathrm{~dB})$ is measured, with a maximum near $2 \mathrm{kHz}$.

Other propagation effects like soil reflection, or the presence of shielding objects, were not considered here. Although these effects could be relevant since they might further change the frequency balance, it would lead to many additional cases to be studied which cannot be captured in a reasonable duration of the test.

A high-order $(n=1000)$ finite-impulse response $(F I R)$ filter has been applied to the recordings to account for the frequency weighting caused by atmospheric absorption and transmission through the window. The use of such a large order filter increases accuracy, and was possible since samples were prepared in advance. A linear phase response has been assured by the chosen filter. For the separately filtered samples of wind turbines, local roads and highways, the equivalent A-weighted sound pressure levels were calculated and further adjusted based on the SNR studied. These samples form the basis for both listening experiments. 


\subsection{Spectro-temporal description of the audio samples}

The evolution over time of the sound pressure level, integrated over 1-s periods, of the nonmixed samples of highway noise, local road noise and wind turbine noise, is shown in Fig. 2. The corresponding spectrum, averaged over the full sample duration, is shown in Fig. 3. These are the filtered samples by the presence of a window and atmospheric absorption that will be sent to the loudspeaker. The room response is not included in these. In addition, a detailed spectrogram of pure wind turbine noise (as originally recorded at $30 \mathrm{~m}$ downwind from the pole) is depicted in Fig. 4. Distinct periodic patterns could be observed at both low and high sound frequencies.

To limit the number of degrees of freedom to be considered in the experiment, each sample is adjusted to $40 \mathrm{dBA}$ equivalent sound pressure level over the 7.5-minutes sample duration. The $L_{\text {Aeq }}$ was chosen for equalization since this quantity is the basis for regulations in many countries and is also the underlying indicator for the day-evening-night equivalent levels as imposed by the European Environmental noise directive (2002/49/EC). This choice, however, does not imply that we assume that this is the best indicator for predicting noise annoyance. Either these full samples are used (with adapted SNR), or extracts are taken.

[FIGURE 2]

[FIGURE 3]

[FIGURE 4]

\section{Listening tests}


All experiments were conducted over a time span of different weeks, mostly in the evening. Up to 4 participants performed the test simultaneously. The participants were not informed about the true purpose of the test which was announced as research about the quality of the living environment. No overview was given on the different parts of the experiment at the start. The same researcher welcomed and guided all participants through the different steps of the experiment that took at most 2 hours. The participants were compensated with a cinema ticket (with a value of 9 Euros) after completion.

\subsection{Annoyance during quiet leisure activity}

In the first non-focused listening experiment annoyance caused by combined exposure to low levels of wind turbine and road traffic noise indoors during a quiet leisure activity was studied.

\subsubsection{Setup of the test room and equipment}

This listening experiment was performed in a rectangular room. Signs or references to the acoustics research group, organizing this experiment, were fully absent. A long curtain divided the room so one half could be decorated as a realistic living room. All equipment was placed behind the curtain out of the participants' sight. It was verified that fan noise of equipment could not be heard inside the living room partition. Experiments were conducted after office hours or during weekends to minimize intruding noise from adjacent rooms or corridors.

The samples were played with a loudspeaker (Adam audio S1X), containing a woofer and tweeter with built-in amplifiers and a subwoofer with lower cut-off frequency of $32 \mathrm{~Hz}$. The loudspeaker setup has a flat frequency spectrum in the audible region. The loudspeakers were positioned inside the room, behind the curtain, near the position of a virtual window. The sound pressure level, spectrally corrected for atmospheric absorption and transmission through a window, was adjusted to $40 \mathrm{dBA} L_{\text {Aeq }}$ at the location of the sofa by changing the volume of the 
amplifier driving the loudspeaker. It was assured that each sample played in this test was 40 dBA LAeq. When combined sounds (e.g. highway noise and wind turbine noise) were played, the levels of the constituting parts were lowered, in order to get $40 \mathrm{dBA} \mathrm{L}_{\text {Aeq }}$ for the combined sample. This level was checked with a sonometer (similar instrumentation as used for the outdoor recordings) at the start of each test. One could argue that the sound pressure level of a local road would be higher than those of a highway further away. However, the choice for an equal $L_{\text {Aeq }}$ for the different stimuli is justified since otherwise the outcome of the test is very likely to be the obvious relationship between loudness and noise annoyance, independently of the detailed characteristics of the sounds and mixtures.

Absorbing material was added to the room to obtain a typical reverberation time of a standard living room. Unrealistic reverberation times might affect the listening experience of the participants. During the setup of the experiment, measurements were performed in compliance with ISO 3382 and ISO 18233. Measured reverberation times were compared to those reported by Diaz and Pedrero (2005), where an extensive measurement campaign was held in more than 3000 furnished living rooms in Madrid, Spain. The reverberation parameter used in the latter study was T20 for octave bands between $125 \mathrm{~Hz}$ and $4000 \mathrm{~Hz}$. Measurements in the current test room at the different octave bands where within $0.1 \mathrm{~s}$ compared to the averaged reported results for rooms with a similar volume.

\subsubsection{Visual setting}

Six different photographs of windows facing a garden were projected in random order on a screen embedded in the curtain dividing the experimental room in two parts. The beamer was positioned so that it was not visible, and it was ensured that the fan noise could not be heard by the participants. The use of garden views should increase the feeling of being at home and distract the participants from the true purpose of the test. A negative visual setting had to be 
avoided since this might increase noise annoyance for a given sound pressure level (Viollon et al., 2002; Li et al., 2010). No pictures of wind turbines were shown in this part of the experiment in order not to give hints on the actual purpose of this test.

\subsubsection{Audio samples}

During the presence of the participants in the room, 6 samples of $40 \mathrm{dBA}$ LAeq, lasting 7.5 minutes each, were played in random order. These samples were:

- Highway noise at $250 \mathrm{~m}$

- Wind turbine noise at $250 \mathrm{~m}$

- Highway noise at $250 \mathrm{~m}$ combined with wind turbine noise at $250 \mathrm{~m}$, with a SNR of the wind turbine noise equal to $0 \mathrm{dBA}$

- Highway noise at 250 m combined with wind turbine noise at $250 \mathrm{~m}$, with a SNR of the wind turbine noise equal to $-10 \mathrm{dBA}$

- Local road traffic noise at $15 \mathrm{~m}$, combined with wind turbine noise at $250 \mathrm{~m}$, with a SNR of the wind turbine noise of $0 \mathrm{dBA}$

- Local road traffic noise at $15 \mathrm{~m}$, combined with wind turbine noise at $250 \mathrm{~m}$, with a SNR of the wind turbine noise of $-10 \mathrm{dBA}$

As the purpose of this test is assessing annoyance, sufficiently long exposure is needed. The selected 7.5-minute period is a compromise between sufficient sample duration and allowing for different SNRs to be tested, while keeping the total experiment duration within reasonable limits to prevent fatigue and disinterest by the participants.

\subsubsection{Test procedure}


Participants were comfortably seated in a living room (see Fig. 5) and instructed to read popular magazines and comic books. It was checked that there were no links to wind turbine noise issues in these. The participants were not allowed to bring their own books, laptops, portable music players nor cell phones. It was asked not to talk during the experiment and not to seek interaction during filling in forms. The noise level was monitored during the full experiment, to ensure that the people were quiet.

\section{[FIGURE 5]}

The order of the audio samples was randomized. Each sample was followed by 1.5 minutes of silence where participants were instructed to answer on paper the following question (originally in Dutch, the participants' mother tongue): "To what degree were you annoyed by the sounds heard in the previous period?" An answering scale ranging from 0 (with the indication "not at all annoyed") to 10 (with the indication "extremely annoyed") was offered. An integer number had to be chosen. Only the extremes in this answering scale were textually labeled.

The projected window views were randomized as well. Each group of participants got a different set of audio-visual combinations. After each test, the following question was asked related to the projected views: "Did you like the projected view during the past period?", and a scale was given between 0 ("liked it a lot") and 10 ("did not like it at all"), where an integer number had to be chosen. Only the extremes in this answering scale were textually labeled.

After playing all six samples and answering each time the annoyance and visual question, people were asked via a written survey: "What sounds do you think you have heard since the start of the experiment?". Following options were given : "road traffic noise", "railway noise", "air traffic noise", "rustling of leafs", "water transport noise", "wind turbine noise", "breaking sea 
waves" ,"people talking" ,"machine noise" ,"noise from fountains/falling water". The participants could make multiple choices. In addition, they could add sound not included in the proposed list.

\subsection{Energetic masking of wind turbine noise by road traffic noise (focused test)}

In a second part of the experiment, the participants were asked to deliberately listen for the presence of wind turbine noise in audio samples in a paired comparison test. The main purpose of this part of the test was finding the detection limit of wind turbine noise submersed in road traffic noise.

\subsubsection{Equipment and setup}

The experiment took place in front of a laptop PC, running a Matlab interface controlling the playback of samples and logging of the answers. The noise fragments were played with circumaural headphones (Sennheiser HD280pro) having a frequency response between +5 and $-5 \mathrm{~dB}$ between $10 \mathrm{~Hz}$ and $5 \mathrm{kHz}$. The amplification of the sound card was set so that $40 \mathrm{dBA}$ was received at the eardrum of a head-and-torso simulator (HATS, Bruel and Kjaer, type 4128C) when using the same headphones as used by the participants. The non-mixed highway noise sample was used for this calibration. This calibration does not ensure exactly the same level of the stimulus as in the first experiment because of the ear canal transfer function, but a very comparable level.

\subsubsection{Audio samples}

The same samples were used as in the annoyance test, but now with a reduced length of $30 \mathrm{~s}$, randomly taken from the longer samples. The wind turbine noise was mixed at SNRs between $30 \mathrm{dBA}$ and $+10 \mathrm{dBA}$ in steps of $10 \mathrm{dBA}$. Both highway noise and local road traffic noise were used as masking sounds. 
For the samples containing highway noise, given its constant character, the actual SNR of the wind turbine was equal to the one in the 7.5-minute test used earlier (within a 0.5-dBA accuracy). When mixing with local road noise recordings, the actual SNR deviates from the long samples, since the number of identifiable passages in the short sample largely influences the local road noise levels. The range of SNRs covered was therefore slightly reduced to $+6.8 \mathrm{dBA}$ and $-24.8 \mathrm{dBA}$ (compared to $+10 \mathrm{dBA}$ and $-30 \mathrm{dBA}$ in case of the highway noise samples). Also the total A-weighted level of the samples, originally aimed at $40 \mathrm{dBA}$, deviated slightly, and differences up to $4 \mathrm{dBA}$ were calculated between the different extracts. It is unlikely that this will influence the effect of SNR that is studied here.

\subsubsection{Visual setting}

The visual setting was a single photograph of multiple wind turbines along an empty road (see Fig. 6), to further stress the focus on wind turbine noise.

[FIGURE 6]

\subsubsection{Test procedure}

The subjects had to listen to the unmixed wind turbine sound recording (also at $40 \mathrm{dBA}$ ) for 30 seconds at the start of the experiment

They were then offered subsequently two samples, where only one contained the wind turbine noise they listened to at the start of this test. The subjects were forced to indicate the sample they thought was containing wind turbine noise before proceeding. Each participant had to evaluate 10 pairs of sounds but in different order. It was allowed to listen several times to the two samples under evaluation before making a choice. The participants did not have to listen to 
the full sample before making their choices. Once the choice was made, going back to the previous evaluation was not allowed.

The pairs that were offered were drawn from both the pool of samples of unmixed road traffic noise and the pool of samples containing wind turbine noise, at different SNRs. Each participant listened to all of the 10 samples in random order. The participants did not have to compare highway noise samples with local road samples.

\section{Test subjects}

Fifty listeners without any history of otological problems participated in the experiment.

\subsection{Hearing status test}

Hearing status was assessed via pure tone audiometry (PTA) carried out in a quiet but not sound-proof room using a regularly calibrated AC5Clinical Computer Audiometer. At the octave band centre frequencies between $125 \mathrm{~Hz}$ and $8000 \mathrm{~Hz}$, hearing thresholds were determined following the modified Hughson-Westlake technique (ISO 8253-1 1989). The hearing threshold is defined as the lowest sound pressure level the subject can detect for half of the tones presented and expressed in $\mathrm{dB} \mathrm{HL}$ (hearing level) with $0 \mathrm{~dB} H \mathrm{HL}$ the hearing threshold of a normal hearing subject. Results are considered normal between $-10 \mathrm{~dB} H \mathrm{HL}$ and $25 \mathrm{~dB} \mathrm{HL}$.

\subsection{Survey}

After completing both experiments and the hearing status test, a survey (on paper) had to be completed by the participants. Apart from some general personal questions (gender, age, professional status and preferred leisure activities), their sensitivity to noise was asked for. The latter was assessed using a 10-question Dutch adaptation of the Weinstein's noise-sensitivity scale (Weinstein, 1978) used previously in large-scale Flemish quality-of-life studies. More 
recently, noise sensitivity questionnaires have been developed assessing noise sensitivity in different daily-life situations (leisure, work, habitation, communication, and sleep) (Schutte et al., 2007). However, the assessment of noise sensitivity based on the questions of Weinstein is still widely used, allowing comparison to other work, and has the advantage of keeping the number of questions limited.

Additionally, people were asked about their living environment in general (e.g. my dwelling is situated in: "an urban environment", "a suburban environment", "a rural environment") and about the presence and visibility of environmental noise sources near their dwellings (more precisely highways, wind turbines, rail tracks, etc.). Finally, their point of view with respect to sustainable and renewable energy was asked (e.g. "Do you use green energy?","Are you a member of an environmental pressure group?").

\subsection{Test panel description}

\section{[FIGURE 7]}

An overview of the test panel is shown by means of the histograms in Fig. 7 . The age of the participants ranged from 19 to 71 . The largest group is between 20 and 25 years old. The other age classes are less populated, but cover a wide span. This age distribution may influence the strength of the reported annoyance (Van Gerven et al., 2009) but the most plausible mechanism for this age dependence is a personal factor: "because of a relatively high level of daily mental workload, the adaptive resources of middle-aged people are pushed to the limit by the presence of noise" which is orthogonal to the sound related factors investigated here. Therefore, it is expected that the relationships and dependences are not affected by the precise age distribution. $54 \%$ of the subjects were female, $46 \%$ male. $40 \%$ were students, $44 \%$ were employed, $6 \%$ were unemployed, $2 \%$ housewife/man, and $8 \%$ were retired. 
$82 \%$ of the participants had a positive attitude towards renewable energy, $18 \%$ called themselves neutral. No one reported to be against renewable energy. Furthermore, $28 \%$ of the test group was user of green energy, and $6 \%$ of the participants were member of an environmental pressure group. The latter group could have either a strong positive attitude towards wind turbines, but also a negative one (Warren et al., 2010). Their share in the test group was too small to further elaborate on.

$8 \%$ was living within $250 \mathrm{~m}$ from a highway (all of them could see the highway), $2 \%$ (1 person) was living within $250 \mathrm{~m}$ from a wind turbine ( $8 \%$ of the participants could see a wind turbine from their dwelling), and 54\% was living within $250 \mathrm{~m}$ from a railway track ( $40 \%$ could see the passing trains). $12 \%$ was living in an urban environment, $44 \%$ in a rural environment, and $44 \%$ in suburban environment.

People living at close distance from a wind turbine are expected to be familiar with the type of sound under study, and will probably have a clear opinion. Only 1 person in the test fell in this group, and in total 4 participants had a view from their dwelling on a single or multiple wind turbine(s).

In general, the test group could be categorized as rather positive/neutral with relation to renewable energy, without being biased by previous experience with wind turbine related annoyance.

The individual answers on the ten noise sensitivity related questions (on a 5-point categorical scale) are summarized per participant by selecting the categorical answer that is most often chosen. In case of a tie, the highest level is selected. A similar processing has been used in Bockstael et al. (2012). Noise sensitivity in the tested group is considered to be rather high. 
Based on the audiometrical test, no one was excluded from the experiment. The hearing threshold is well below the sound pressure levels used in the experiments.

\section{Results}

\subsection{Annoyance by wind turbines noise}

The results of the annoyance test are presented as boxplots (see Fig. 8 and Fig. 9), giving an indication of the distribution of the ratings for the different samples. The (middle) horizontal line in the box indicates the median of the data. The box is closed by the first and third quartile. The whiskers extend to 1.5 times the interquartile distance above the maximum value inside the box, and to 1.5 times the interquartile distance below the minimum value inside the box. Data points that fall outside these limits are considered as outliers and are indicated with the plus-signs.

Results are given either as relative ratings (Fig. 8), or absolute ratings (Fig. 9). Personal factors and overall rating strategy may introduce additional variance in the results. Therefore, the average of the ratings for the 6 samples given by a participant is subtracted from each individual rating to obtain what is called the relative rating. This approach is inspired by - but not completely the same as - master scaling (Berglund, 1991). This operation decreases overlap in the distributions when comparing the different samples and clarifies the general annoyance rating of the different samples.

One-way analysis-of-variance indicates clear differences in the average rating by the test panel of the different samples (F-value equal to $30.3, p<0.001$ ). Different multiple comparison tests (Tukey-Kramer, Bonferonni) show no differences between wind turbine noise alone and highway noise alone at the 1\%-significance level. Consequently, combinations at different SNRs for these types of sounds have a similar noise annoyance rating too. In general, the participants 
do not rate (pure) wind turbine noise as more annoying than e.g. highway noise at the same (low) equivalent noise level.

The samples containing local road traffic noise were rated as significantly more annoying than the others. The two SNRs considered for the local road samples cannot be considered different even at the 1\%-significance level in the multiple comparison tests. Since the annoyance rating is higher than in case of unmixed wind turbine noise, it can be concluded that local road traffic noise (at close distance) is perceived as more annoying than wind turbine noise at the same equivalent indoor noise level. It has to be stressed that this finding is based on low (but realistic) indoor noise levels (with closed windows), and for participants not familiar with wind turbine noise.

Potential synergetic effects between local road traffic noise and wind turbine noise cannot be excluded based on the current experiment. In Ohrström et al. (2007), e.g., it was found that in areas exposed to both railway and road traffic, the proportion of annoyed people is significantly higher than in areas with one dominant noise source (railway noise or road traffic noise) with the same total sound exposure. One of the mechanisms that could lead to synergetic effects involves recognizing multiple sounds in the sonic environment (Botteldooren et al., 2002). The absence of clues to the presence of wind turbines may lower the probability for detecting a second sound source and thus also the increase in overall annoyance. The SNR of the wind turbine noise, relative to local road traffic noise, does not seem to play a role here. This could indicate that such effects, if present, are not strong.

The differences in temporal characteristics could explain at least part of the fact that local road noise is perceived as more annoying at the same equivalent level. In case of highway noise, a similar temporal structure is found as with the wind turbine noise. In case of local road traffic noise, variation in level over time is much stronger. At the low noise levels considered in the 
experiment, noticing is strongly related to annoyance (De Coensel et al., 2009) and hence the higher peak levels in the local road traffic may explain this.

[FIGURE 8]

[FIGURE 9]

Although there was a non-statistically significant preference for some of the garden views (not shown), the visual setting could not be linked with reported noise annoyance. Note that different garden views were mainly used to hide the real purpose of the test. No further analysis is therefore performed on this aspect of the experiment.

\subsection{Recognition of wind turbine noise}

At the end of the exposure to the 6 samples, participants were asked which sounds they thought they had heard. These answers are summarized in Table 1. Almost all participants (96\%) recognized road traffic noise. Although there were no direct hints towards wind turbines, $44 \%$ of the participants recognized wind turbine noise. The experience in the test group with this type of noise was limited, as discussed earlier. The survey indicated that only 1 person was living in the close vicinity of a wind turbine (less than $250 \mathrm{~m}$ ), and 3 additional participants could see a wind turbine from their dwelling. This could indicate that the noise by a wind turbine corresponds to the expectation of about half of the people. Surprisingly, $48 \%$ of the people thought to have recognized air traffic noise, although this type of sound was not present in the samples, and there were no fly-overs by airplanes at the test location during the listening experiments. This can be explained by the fact that there are similarities between these two types of sound. The noise generation mechanism is primarily of an aerodynamic nature. It has indeed been observed previously that people living close to wind turbines describe the sound as "a never landing aircraft". In the work by Pedersen et al. (2009), the exposure-annoyance 
response curves of aircraft noise and wind turbine noise were found to lie close to each other. About 38\% choose the general description "machine noise" from the list. Breaking sea waves were recognized by $28 \%$ of the people. This type of sound is known to have similar characteristics as highway noise. In the section "others", people answered "birds", "seagulls", "airconditioning system" and "dishwasher".

\section{[TABLE 1]}

\subsection{Detection of wind turbine noise}

The second listening experiment investigates the possibility to detect wind turbine noise within background noise in a focused listening task (with headphones), i.e. the possibility to energetically mask wind turbine noise by other noise sources. Results are analyzed using mixed model logistic regression with as outcome variable the possibility of correctly identifying the fragment with wind turbine noise out of two fragments (binary outcome, wrong or right). The fixed factors are type of background noise (highway or local road) and SNR nested within the type of background noise (as wind turbine noise is presented at slightly different SNRs for fragments with noise from highways compared to those from local roads). This analysis fails to demonstrate an overall significant difference between the energetic masking capabilities of highway and local road noise as such $(p=0.30)$, but the influence of the SNR clearly depends on the type of background noise as shown in Fig. 10.

In case of masking by highway noise, results show a clear and linear trend for the probability of correct answers as a function of SNR $(p<0.001)$. The larger the SNR, the larger the fraction of the participants that was able to identify the sample containing the wind turbine noise. For a SNR equal to $+10 \mathrm{dBA}$, near $80 \%$ of the participants gave a correct answer. A reduction in the SNR with $10 \mathrm{dBA}$ corresponds to a reduction in the percentage of correct answers with roughly 
$10 \%$. Given the fact that participants were forced to give an answer, a detection rate of $50 \%$ would indicate a pure guess. Following the logistic mean response function, this corresponds to a SNR of -23 dBA in case of highway noise. Given the limited number of respondents in the listening tests, the 95\%-confidence intervals cover a rather wide range of SNR values; the upper limit is near $-15 \mathrm{dBA}$ at the $50 \%$ detection rate. Pedersen et al. (2010) showed a significant reduction of annoyance (long-term evaluation) in case the (predicted) SNR compared to background noise was near $-20 \mathrm{dBA}$. The slightly lower value found here could be attributed to the specific test setup, where subjects were asked to strongly focus on the wind turbine sound with almost no distraction. Also, the use of long-term averaged level predictions in Pedersen et al. (2010), an exposure indicator that might significantly differ from the instantaneous levels used here, could lead to deviations in the exact SNR. Bolin et al. (2010) found SNRs at detection thresholds, based on a similar experiment as in this study, between $-10 \mathrm{dBA}$ and -5 $\mathrm{dBA}$, depending on the type of masker (wind-induced vegetation noise by coniferous trees and by deciduous trees, and sound from sea waves), and whether single or multiple wind turbines were present in the samples offered to the participants. This could indicate that these types of natural sounds are more effective in masking wind turbine noise than highway noise at low sound pressure levels. When comparing SNRs needed for masking between different studies, care is needed since spectro-temporal characteristics of wind turbine noise may differ strongly.

In case of wind turbine samples submersed in local road traffic noise, the influence of SNR on the correct answer rate is less consistent $(p=0.12)$. The average detection rate for SNRs larger than zero, based on the raw data, is very similar than in case of the samples with continuous highway noise. At smaller SNRs, the trend is much less clear, yielding large confidence intervals as shown in Fig. 10. An important result of this unmasking test is that local roads are much less suited to energetically mask wind turbine noise than highway noise at the same equivalent noise level. Given the large temporal variability in the sound pressure level for this type of sound 
source, wind turbine noise could be well heard in the silent periods in between the distinct car passages. Such passages are indeed dominant for A-weighted equivalent noise levels, which is kept constant in this study. No clear conclusions could be drawn with relation to the needed SNR to achieve energetic masking.

\section{[FIGURE 10]}

\subsection{Exploring underlying mechanisms}

This section explores how the current experiment could contribute to the understanding of underlying mechanisms resulting in the frequently observed higher reported annoyance by wind turbine noise than continuous road traffic noise at the same $L_{\text {Aeq. }}$. Reporting noise annoyance is a complex process that involves hearing, listening, and appraisal mechanisms. The main aspects of these processes that could differ between wind turbine noise and continuous road traffic noise are highlighted below.

Firstly, one has to realize that in most practical situations and also in the current experiment, wind turbine noise exposure has low equivalent levels. Especially in this exposure regime noticing the sound is an important prerequisite for annoyance (De Coensel et al., 2009). Could wind turbine noise attract attention more strongly because of particular acoustic features? The focused listening test shows indeed that unmasking wind turbine noise from continuous traffic noise seems possible at very low SNRs. This proposes another research question: are some people more capable of detecting wind turbine sound characteristics in traffic noise than others? The plasticity and diversity of the human auditory system may even lay a physiological basis for these inter-individual differences. To investigate this, results of experiments on informational and energetic masking will be combined (detection and recognition). 
Noticed environmental sound is given meaning and is appraised within a context and with certain expectations (Botteldooren et al., 2011). In case of wind turbines, this appraisal may lead to higher annoyance because these sources are generally new and often placed at locations where people expected quietness. In the first part of the experiment, participants were not aware that wind turbine noise was part of the experiment which may explain why on average reported annoyance at the same LAeq was not higher than reported annoyance for highway noise. To strengthen this hypothetical mechanism, it is investigated whether those participants stating that they heard a wind turbine where indeed those that did report higher annoyance for wind turbines (recognition and annoyance).

Combining both hypotheses above, it is worthwhile to explore whether those participants that could unmask wind turbine noise more easily in the last part of the experiment were indeed those that reported higher noise annoyance during the wind turbine sound fragments (detection and annoyance).

\section{Detection and recognition}

People's capability to detect wind turbine noise is studied by modeling the probability of correct wind turbine detection in the second experiment. The question is whether participants that are in general better in recognizing wind turbine noise perform also better in this focused-listening task. General recognition capability is based on source recognition performance after the first experiment by grouping these data into four categories: people unambiguously recognizing wind turbines, people naming sources very similar to wind turbines (i.e. machine noise and/or airplane noise), people naming both wind turbines and similar sources and finally people naming neither wind turbines nor wind turbine-like sources. 
Fig. 11 illustrates that people not recognizing wind turbines nor similar sources, are indeed worse in detecting wind turbine noise in the focused task. By contrast, those unambiguously recognizing wind turbines or similar sources both perform best in the second experiment, whereas participants who name wind turbines and similar sources take an intermediate position. One possible explanation for this last finding could be that participants naming more sources generally tend to guess more.

Mixed model linear regression with correct detection as outcome variable and as independent variables subject (random) and general recognition (fixed, $\mathrm{p}=0.07$ ) reveals that the differences shown in Fig. 11 are marginally statistically significant.

The above analysis did not include the type of masker (highway or local road) and SNR as (potentially) explaining variables. When assessing the relationship between detection and recognition, the effect of recognition is strongest for the fragment where the wind turbine noise is most detectable, i.e. in highway noise with SNR of $+10 \mathrm{~dB}$. With decreasing SNR including $20 \mathrm{~dB}$, participants not recognizing wind turbines nor similar sources are least capable of detecting it. At SNR -30 dB, the influence of general recognition is less consistent, most likely because participants had to guess as the masker makes the wind turbine nearly inaudible. When only local road fragments are considered, regardless of the SNR, general recognition appears to have a similar relationship with wind turbine detection as described above.

\section{[FIGURE 11]}

\section{Recognition and annoyance}

To investigate the relationship between source recognition and noise annoyance, the reported annoyance in the first experiment is plotted as a function of source recognition (see Fig. 12). Not 
recognizing wind turbines at all seems to be associated with less annoyance, but the variation in reported annoyance is too high to detect statistically significant differences. The trend is visually confirmed when annoyance is investigated only for the noise fragments containing highway noise as masker, but are less consistent for fragments with noise from local roads or only wind turbines. When categorizing the reported annoyance in a two-level variable (annoyance/no annoyance), mixed model logistic regression with subject as a random factor shows that participants recognizing no wind turbines nor similar sources report significant less annoyance $(\mathrm{p}<0.05)$. In this modell background noise (more precisely the 6 specific combinations of wind turbine, highway and local road noise) was included as a fixed factor $(p<0.05)$..

[FIGURE 12]

\section{Detection and annoyance}

Similar analyses are performed to address a possible relationship between the annoyance level reported after exposure to wind turbines in background noise (local road or highway) and the participants' ability to hear the wind turbine noise in that particular type of background noise (i.e. again local road or highway). Hearing of wind turbine sound was quantified per subject based on the total number of correctly identified fragments in the second experiment, separately for the fragments with local road or highway as background noise. However, no significant results were found here, neither when the reported annoyance levels were as such used as outcome variable nor when they were categorized to a dichotomous variable (annoyance/no annoyance).

A statistically significant $(p=0.01)$ but moderate $(R=0.36)$ correlation could be found between the success rate in detecting the samples containing wind turbine noise in the focused test, and annoyance by the pure wind turbine sample in the non-focused test. Note that the general 
annoyance for this sample was limited and not statistically significant different from the highway noise sample. For the latter, on the other hand, such a correlation could not be found.

\section{Noise sensitivity and personal traits}

In a final analysis, it is studied whether self-reported noise sensitivity can be linked to the perceived annoyance, the recognition, and the detection of wind turbine noise submersed in road traffic noise.

Subsequent regression analyses are carried out with each time summarized noise sensitivity as independent fixed factor and respective outcome variables annoyance (mixed model linear regression including random factor subject), recognition of wind turbines noise (single fixed factor logistic regression) and probability of detection (mixed model logistic regression including random factor subject). None of these analyses are able to reveal a statistical significant influence of noise sensitivity on reported annoyance or on the ability to identify and/or detect wind turbine noise $(\alpha=0.05)$.

A possible reason for the limited influence of noise sensitivity on annoyance are the low levels at which the experiments were performed. Miedema and Vos (2003) and Lercher (1995) showed that noise sensitivity becomes especially important at higher exposure levels in case of self-reported noise annoyance and sleep disturbance, respectively. Also in a recent study on the quiet side effect, focusing on dwellings highly exposed to road traffic noise, noise sensitivity was shown to be a relevant factor as well (Van Renterghem and Botteldooren, 2012). However, care is needed when analyzing this parameter as the spread over the different noise sensitivity classes is rather limited in the current small data set, making it difficult to find statistically significant influences. 
To investigate the influence of other personnel traits in these experiments, similar analyses are carried out separately for fixed independent variables gender, age, professional status, and hearing threshold. Two models give marginally significant results: younger people are more capable of unambiguously recognizing wind turbine noise after the first listening experiment $(p=0.08)$ and students perform less good in the focused experiment compared to employed participants or participants without paid employment $(p=0.08)$. In general, however, personal characteristics fail to account for the here observed inter-individual differences in annoyance and auditory scene analysis $(\alpha=0.05)$.

\section{Conclusions and discussion}

A multi-stage listening experiment was performed, consisting of an annoyance assessment test during a quiet leisure activity, a question related to the recognition of wind turbine noise, a focused listening experiment with headphones to detect wind turbine noise submersed in road traffic noise, an audiometric test, and a small survey to reveal personal traits. The test group consisted of 50 participants, which could be categorized as having a positive to neutral attitude with relation to renewable energy. The participants were not biased by previous experience with wind turbine related noise. All participants had normal hearing abilities and rather sensitive to noise as assessed by a shortened version of the Weinstein questionnaire. The number of participants can be considered as rather small, especially in the viewpoint of noise annoyance testing. At the other hand, such a limited group allowed to perform different types of tests, and to combine such data, in order to explore underlying mechanisms with a reasonable effort.

In the annoyance test, wind turbine noise, either combined with highway noise or not, did not increase the average noise annoyance rating for participants not aware of the presence of wind turbine noise. Local road traffic noise, combined with wind turbine noise, was considered to be 
significantly more annoying, much more than pure wind turbine noise at the same equivalent $\mathrm{A}$ weighted level.

Two critical remarks need to be made. Firstly, although many researchers before have used very short sound signals to investigate annoyance, the authors are convinced that reported noise annoyance (in the current, common use of the term) cannot be assessed using short exposure. Here, we used 7.5-minute sound samples and distracted the participants by giving them light literature. Yet the time interval may still be too short to observe the whole spectrum of mechanisms (e.g. coping, adaptation, focusing, ...) that lead to reporting (long-term) noise annoyance. Secondly, the limited number of participants - which is however comparable to the sample size used in previously reported lab experiments looking at wind turbine noise perception (Bolin et al., 2010; Lee et al., 2012) - may prevent differences from becoming significant. Notwithstanding these limitations, it can still be concluded that the difference in noise annoyance between highway traffic and less dense traffic at the same $L_{\text {Aeq }}$ is significantly larger than the difference between noise annoyance caused by highway traffic and wind turbine noise in case the sound source is unknown beforehand.

Noise from a single wind turbine, submersed in highway noise, can easily be detected once it is known and the detection limit is as low as $-23 \mathrm{dBA}$. This finding is close to a previously reported SNR (Pedersen et al., 2010) based on predicted levels. In case of local road traffic noise, given its dynamic nature, a detection limit could not be derived within the limits set in the current experiment.

The fact that the annoyance level neither increased nor decreased when wind turbine noise was mixed with road traffic noise indicates the absence of masking or synergetic effects. At first sight, these findings seem to contradict earlier findings based on reported noise annoyance at home (Janssen et al., 2011; Pedersen and Persson-Waye, 2004; Pedersen et al., 2009). 
However, in the case of noise annoyance at home, participants know that the wind turbine is present and might listen for its sound, potentially triggered by visual cues given by the moving blades. The second part of the experiment indicates that this unmasking would indeed be possible even when the wind turbine noise is embedded in highway noise at a very small signal to noise ratio.

In practice, refraction in the atmosphere could play an important role when looking at masking of wind turbine noise. Road traffic noise is generated at low heights (Jonasson, 2007). This means that refraction is enhanced (see e.g. ISO9613-2) compared to a sound source at a larger height like a wind turbine. For upwind receivers, the masker (road traffic noise) could be highly reduced in case an acoustic shadow zone is formed. During such episodes, wind turbine noise could be highly audible. As a general conclusion, masking wind turbine noise with road traffic noise is expected to be difficult to realize.

Combined analysis of the two tests performed in this experiment supports the hypothesis that there is a personal factor that can influence the ability of people to detect and recognize wind turbine noise. Indeed, those participants that did not mention having heard wind turbines or any similar source after the first experiment (recognition) performed significantly worse in the identification task. In fact they did hardly better than pure guessing (50\% correct). This might be explained e.g. by early childhood shaping of the brain (Chang et al., 2003) and thus fundamental differences in listening capabilities, but the current experiment cannot formally exclude the more trivial explanation that some participants simply do not make any effort to answer the more difficult questions. In this analysis, recognizing wind turbine noise and similar sounds has been pooled. Indeed, when asked about the sounds they thought to have heard 
after the first experiment, about half of the test group mentioned air traffic noise and a large third machine noise. These people detected the sound but could not place it.

In line with the previous paragraph, participants that state after the first test that they have recognized wind turbine noise or a similar sound, report statistically higher annoyance in the test. This could confirm the hypothetical causal path for noise annoyance starting with noticing the sound followed by an appraisal step. There might still be two reasons why some participants recognize more sounds. The first is the inter-individual difference in capability to identify wind turbine sound that was already mentioned. The second is that some participants could have been paying more attention to the sound during the test, thus being more annoyed at the one hand, and recognizing more sounds at the other hand. Selective attention indeed seems to be an important factor in fine-tuning auditory scene analysis (Fritz et al., 2007) and thus participants being less focused on the magazines and comic books that were provided as a distracter in the test might spend more attention on identifying different sounds in the acoustic scene.

To distinguish between the attention and capability pathways mentioned in the previous paragraph, the ability to detect wind turbine noise in the second test can be related to the annoyance reported in the first test. This relationship proved to be weak. Thus as the relationship between recognizing sounds and annoyance is strong, the relationship between being able to detect wind turbine sound and recognizing more sounds is weak and the relationship between being able to detect wind turbine sound and annoyance is practically nonexisting, the existence of an underlying factor that affects both annoyance and recognizing sound sources is very likely. This does not prove that this factor is attention related, but at least the amount of attention paid to the sound environment during the test is a plausible explanation. 
In summary, the experiment reported in this paper supports the hypothesis that previous observations, reporting that retrospective annoyance for wind turbine noise is higher than that for highway noise at the same equivalent noise level, is grounded in higher level appraisal, emotional, and/or cognitive processes. In particular, it was observed that wind turbine noise is not so different from traffic noise when it is not know beforehand. In focused listening, on the other hand, it has enough distinctive features to allow detecting even at very low SNRs. Thus it can be expected that focusing, triggered by more generic appraisal of the presence of wind turbines, could increase annoyance considerably. It was also shown that there are probably inter-individual differences allowing some people to detect and recognize wind turbine noise more easily even if its presence is not revealed. Other inter-individual differences may relate to sensitivity to being distracted from light tasks by paying attention to the sound environment. Further experiments are needed to reject alternative explanations for the observations.

\section{References}

Bakker R, Pedersen E, van den Berg G, Stewart R, Lok W, Bouma J. Impact of wind turbine sound on annoyance, self-reported sleep disturbance and psychological distress. Sci Tot Environ 2012;425:42-51.

Berglund B. Quality assurance in environmental psychophysics", in Bolanowski S, Gescheider G (Eds.), Ratio Scaling of Psychological Magnitudes - In Honor of the Memory of S. S. Stevens. (L. Erlbaum Associates, Hillsdale, New Jersey, 1991).

Bockstael A, Dekoninck L, Can A, Oldoni D, De Coensel B, Botteldooren D. Reduction of wind turbine noise annoyance: an operational approach. Acta Acust Acust 2012;98:392-401. 
Bolin K. Prediction Method for Wind-Induced Vegetation Noise. Acta Acust Acust 2009;95:607619.

Bolin K, Bluhm G, Eriksson G, Nilsson M. Infrasound and low frequency noise from wind turbines: exposure and health effects. Environ Res Lett 2011;6:035103.

Bolin K, Nilsson M, Shafiquzzaman K. The Potential of Natural Sounds to Mask Wind Turbine Noise. Acta Acust Acust 2010;96:131-137.

Botteldooren D, Lavandier C, Preis A, Dubois D, Aspuru I, Guastavino C, Brown L, Nilsson M, Andringa T. Understanding urban and natural soundscapes", Proceedings of Forum Acusticum, Aalborg, Denmark, 2011.

Botteldooren D, Verkeyn A. Fuzzy models for accumulation of reported community noise annoyance from combined sources. J Acoust Soc Am 2002;112:1496-1508.

Chang E, Merzenich M. Environmental noise retards auditory cortical development. Science 2003;300:498-502.

De Coensel B, Botteldooren D, De Muer T, Berglund B, Nilsson M, Lercher P. A model for the perception of environmental sound based on notice-events. J Acoust Soc Am 2009;126:656665.

Diaz C, Pedrero A. The reverberation time of furnished rooms in dwellings" Appl Acoust 2005;66:945-956.

Fégeant $O$. Masking of wind turbine noise: Influence of wind turbulence on ambient noise fluctuations. Technical report 2002:12, Department of Civil and Architectural Engineering, Royal Institute of Technology, Sweden (2002). 
Fégeant O. Wind-induced vegetation noise. part 1: A prediction model. Acta Acust Acust 1999;85:228-240.

Fritz J, Elhilali M, David S, Shamma S. Auditory attention - focusing the searchlight on sound, Curr Opin Neurobiol 2007;17:437-455.

Hubbard H, Shepherd K. Aeroacoustics of large wind turbines J Acoust Soc Am 1991;89:24952508.

ISO 8253-1:1989 Acoustics - audiometric test methods - Part 1: Basic pure tone air and bone conduction threshold audiometry. International Organisation for Standardisation, Geneva, Switzerland, 1989.

ISO 9613-1:1996 Acoustics - attenuation of sound during propagation outdoors - Part 1. International Organisation for Standardisation, Geneva, Switzerland, 1996.

ISO 9613-2:1996 Acoustics - attenuation of sound during propagation outdoors - Part 2. International Organisation for Standardisation, Geneva, Switzerland, 1996.

ISO 3382-1:2009 Acoustics -- Measurement of room acoustic parameters - Part 1: Performance spaces. International Organisation for Standardisation, Geneva, Switzerland, 2009.

ISO 18233:2006 Acoustics - Application of new measurement methods in building and room acoustics. International Organisation for Standardisation, Geneva, Switzerland, 2006.

Janssen S, Vos H, Eisses A, Pedersen E. A comparison between exposure-response relationships for wind turbine annoyance and annoyance due to other noise sources. J Acoust Soc Am 2011;130:3746-3753.

Jonasson H. Acoustical source modelling of road vehicles, Acta Acust Acust 2007;93:173-184. 
Lee S, Kim K, Choi W, Lee S. Annoyance caused by amplitude modulation of wind turbine noise. Noise Control Eng 2011;59:38-46.

Lercher P. Distinguishing effects modifiers of psychological morbidity associated with traffic noise exposure. Epidemiology 1995, S28, P085.

$\mathrm{Li} \mathrm{H}$, Chau C, Tang S. Can surrounding greenery reduce noise annoyance at home?" Sci Total Environ 2010;408:4376-4384.

Miedema $\mathrm{H}$, Vos $\mathrm{H}$. Noise sensitivity and reactions to noise and other environmental conditions. J Acoust Soc Am 2003;113:1492-1504.

Møller H, Pedersen C. Low-frequency noise from large wind turbines. J Acoust Soc Am 2011;129:3727-3744.

Moorhouse A, Hayes M, von Hünerbein S, Piper B, Adams M. Research into aerodynamic modulation of wind turbine noise: final report, Technical Report, Department for Business, Enterprise and Regulatory Reform, UK (2007).

Ohrström E, Barregård L, Andersson E, Skånberg A, Svensson H, Angerheim P. Annoyance due to single and combined sound exposure from railway and road traffic. J Acoust Soc Am 2007;122:2642-2652.

Palmer W. A new explanation for wind turbine whoosh—wind shear," in Proceedings of Third International Meeting on Wind Turbine Noise, Aalborg, Denmark (2009).

Pedersen E, Larsman P. The impact of visual factors on noise annoyance among people living in the vicinity of wind turbines. J Environ Psych 2008;28:379-389. 
Pedersen E, Persson-Waye K. Perception and annoyance due to wind turbine noise-a doseresponse relationship. J Acoust Soc Am 2004;116:3460-3470.

Pedersen E, Persson-Waye K. Wind turbine noise, annoyance and self-reported health and well-being in different living environments. Occup Environ Med 2007;64:480-486.

Pedersen E, van den Berg F, Bakker RH, Bouma J. Response to noise from modern wind farms in The Netherlands. J Acoust Soc Am 2009;126:634-43.

Pedersen E, van den Berg F, Bakker R, Bouma, J. Can road traffic mask sound from wind turbines? Response to wind turbine sound at different levels of road traffic sound. Energy Policy 2010;38:2520-2527.

Quirt J. Sound transmission through windows II. Double and triple glazing. J Acoust Soc Am $1983 ; 74: 534-542$.

Salt A, Hullar T. Responses of the ear to low frequency sounds, infrasound and wind turbines. Hearing Research 2010;268:12-21.

Schutte M, Marks A, Wenning E, Griefahn B. The development of the noise sensitivity questionnaire. Noise \& Health 2007;9:15-24.

van den Berg G. Effects of the wind profile at night on wind turbine sound", J Sound Vib $2004 ; 277: 955-970$.

Van Gerven P, Vos H, Boxtel M, Janssen S, Miedema H. Annoyance from environmental noise across the lifespan. J Acoust Soc Am 2009;126:187-194.

Van Renterghem T, Botteldooren D. Focused study on the quiet side effect at dwellings highly exposed by road traffic noise. Int J Environ Res Public Health 2012;9:4292-4310. 
Viollon S, Lavandier C, Drake C. Influence of visual setting on sound ratings in an urban environment. Appl Acoust 2002;63:493-511.

Warren C, Lumsden C, O'Dowd S, Birnie R. "Green on green”: public perceptions of wind power in Scotland and Ireland. J Environ Plann Man 2010;48,853-875.

Weinstein N. Individual differences in reactions to noise: A longitudinal study in a college dormitory. J Appl Psych 1978;63:458-466. 


\section{FIGURE CAPTIONS}

Fig. 1. Situation sketch near the wind turbine. The location where recordings were made is indicated with the red cross.

Fig. 2. Sound pressure levels (indoors) in function of time, integrated over 1-s intervals, of nonmixed highway noise, local road traffic noise, and wind turbine noise.

Fig. 3. Spectrum (indoors), averaged over the full sample duration in case of non-mixed highway noise, local road traffic noise, and wind turbine noise.

Fig. 4. Spectrogram of pure wind turbine noise as (originally) recorded at $30 \mathrm{~m}$ from the pole donwnwind. The sound pressure levels (unweighted) are expressed relative to the maximum level observed over all frequency components in the 10-second fragment considered.

Fig. 5. Photograph of the test room used for the quiet leisure activity.

Fig. 6. Computer interface (in Dutch) used for pair-wise comparison of two samples, where one of these contained wind turbine noise.

Fig. 7. Histograms showing the distribution over age, linearly averaged PTA levels over both ears, and self-reported noise sensitivity (on a 5-point categorical scale, where 1 means "insensitive to noise" and 5 "highly sensitive to noise").

Fig. 8 Boxplots showing the distribution of annoyance ratings for the different samples, on a relative scale ("wt"=wind turbine, "hw"=highway noise, "Ir"=local road. The SNR of the wind turbine noise in case of mixed samples is put in between brackets).

Fig. 9. See caption of Fig. 8, but now the original, absolute scale is used (with 0 meaning "not at all annoyed" and 10 meaning "extremely annoyed"). 
Fig. 10. Probability of correctly identifying wind turbine noise in the focused listening test as a function of SNR, for highway noise and local road noise. The full lines indicate the predicted probabilities using logistic regression, the dashed lines the 95\%-confidence intervals. The open circles indicate the average response of all participants for the SNRs where a sample has been provided (raw data). The cross indicates the detection limit (probability equal to 0.5 ) for wind turbine noise submersed in highway noise samples.

Fig. 11. Percentage of correctly identified fragments containing wind turbine noise as a function of source recognition by the participants naming (a) only wind turbines, (b) sources similar to wind turbine noise, (c) naming both wind turbine and similar sources, and (d) naming neither wind turbine nor similar sources.

Fig. 12. Percentage of noise annoyed (as a dichotomous variable) participants as a function of source recognition by the participants naming (a) only wind turbines, (b) sources similar to wind turbine noise, (c) naming both wind turbine and similar sources, and (d) naming neither wind turbine nor similar sources. 


\section{TABLE CAPTIONS}

Table 1. Fraction of participants indicating that a specific type of sound was present during the non-focused listening experiment. 


\begin{tabular}{ccc}
\hline type of sound & $\begin{array}{c}\text { fraction of people indicating to } \\
\text { have recognized this sound }\end{array}$ & present in samples? \\
\hline Road traffic noise & 0.96 & yes \\
Air traffic noise & 0.48 & no \\
Wind turbine noise & 0.44 & yes \\
Machine noise & 0.38 & no \\
Breaking sea waves & 0.28 & no \\
Rustling of leafs & 0.22 & no \\
Rail noise & 0.2 & no \\
Fountains/falling water & 0.12 & no \\
People talking & 0.06 & no \\
Water transport noise & 0.06 & \\
\hline
\end{tabular}


Figure 1

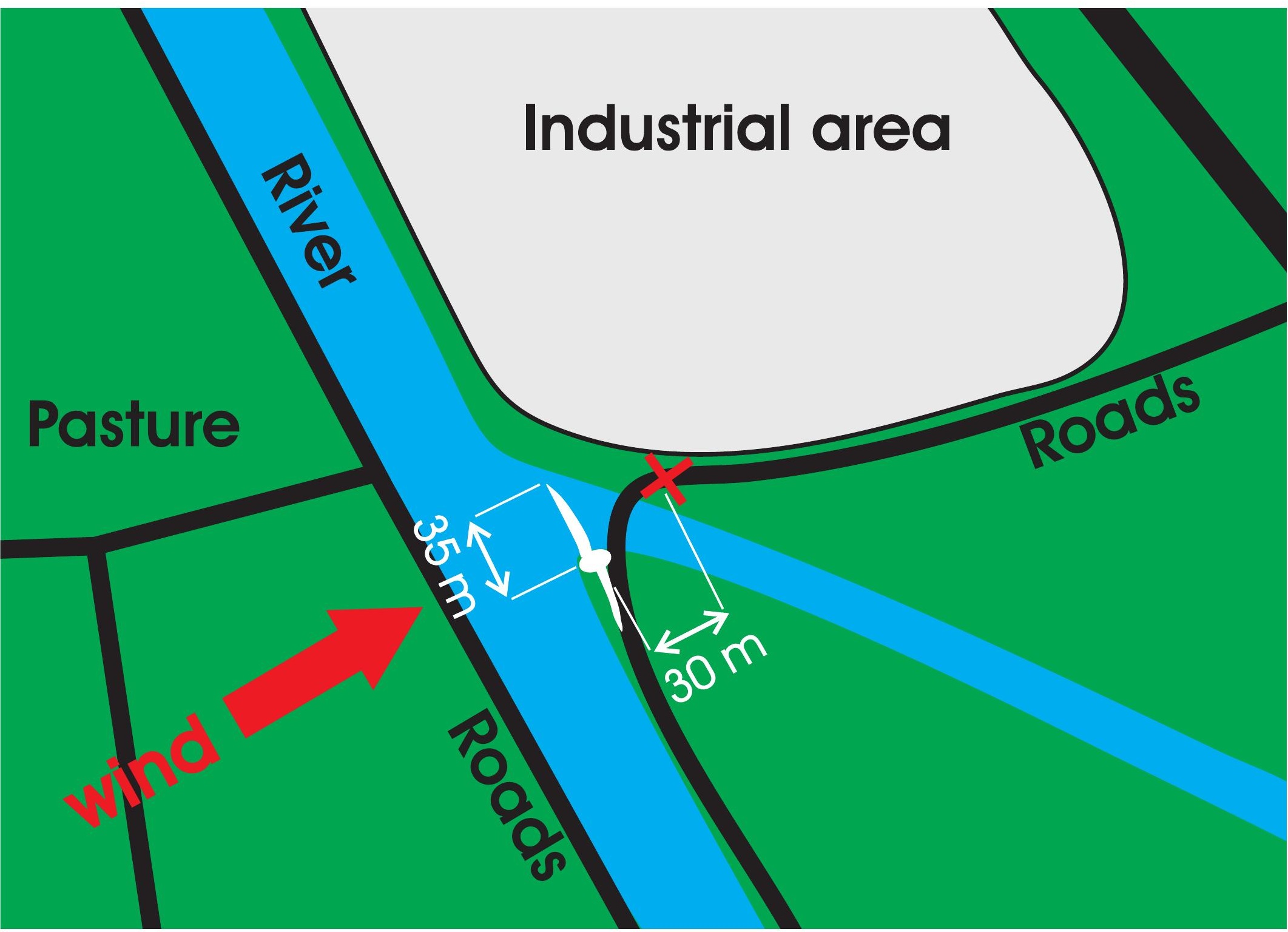


Figure 2

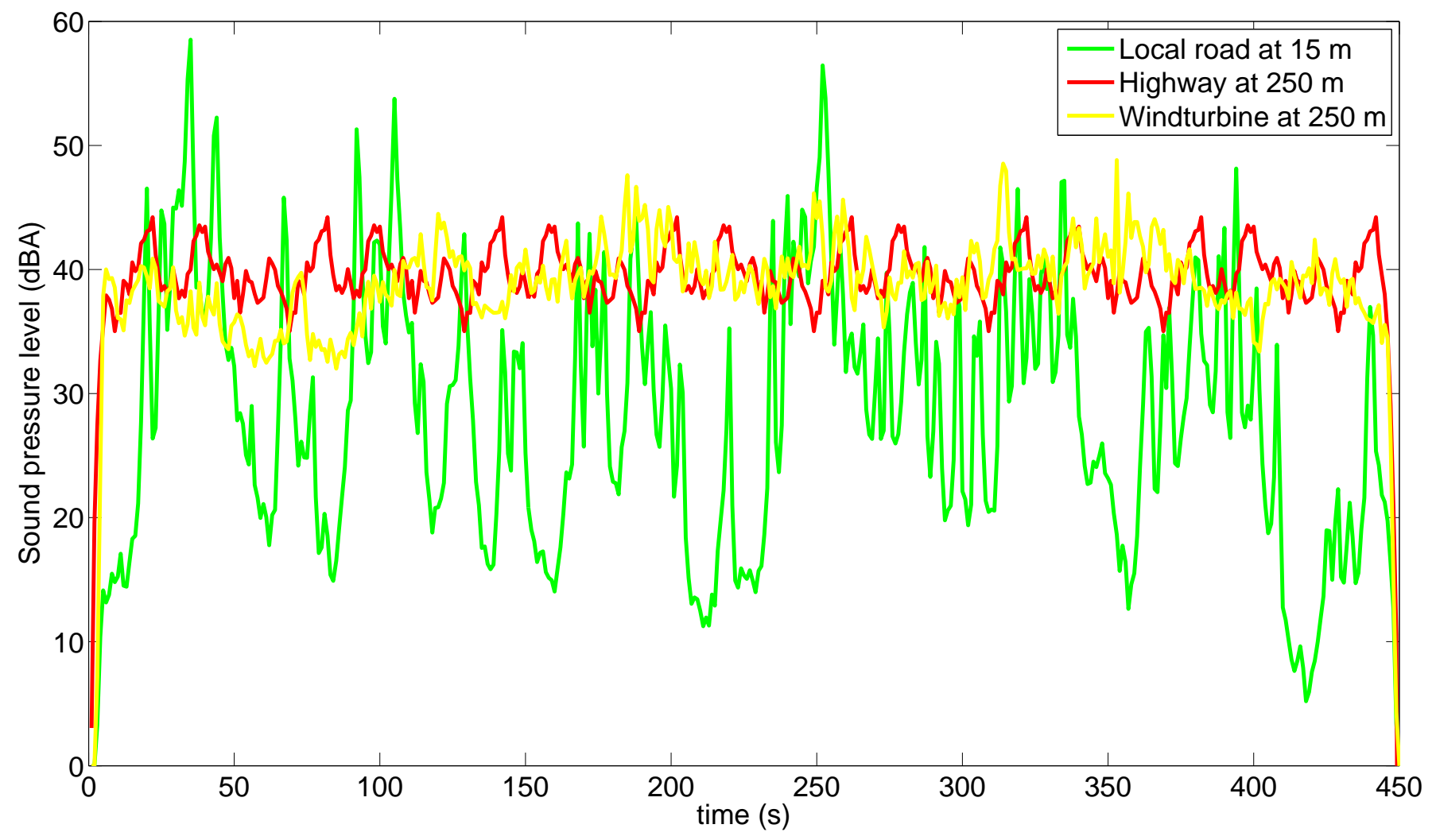


Figure 3

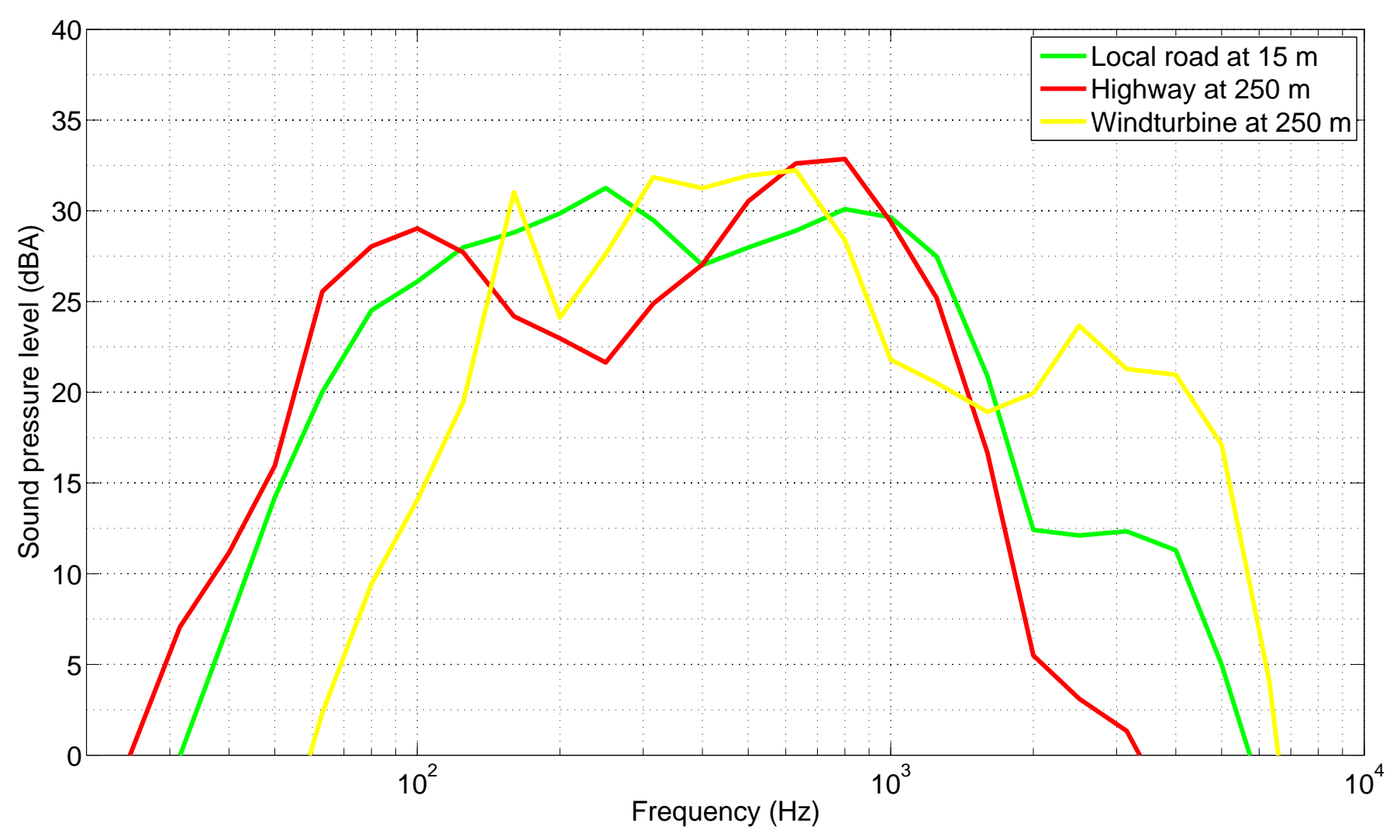

Frequency $(\mathrm{Hz})$ 
Figure 4

C

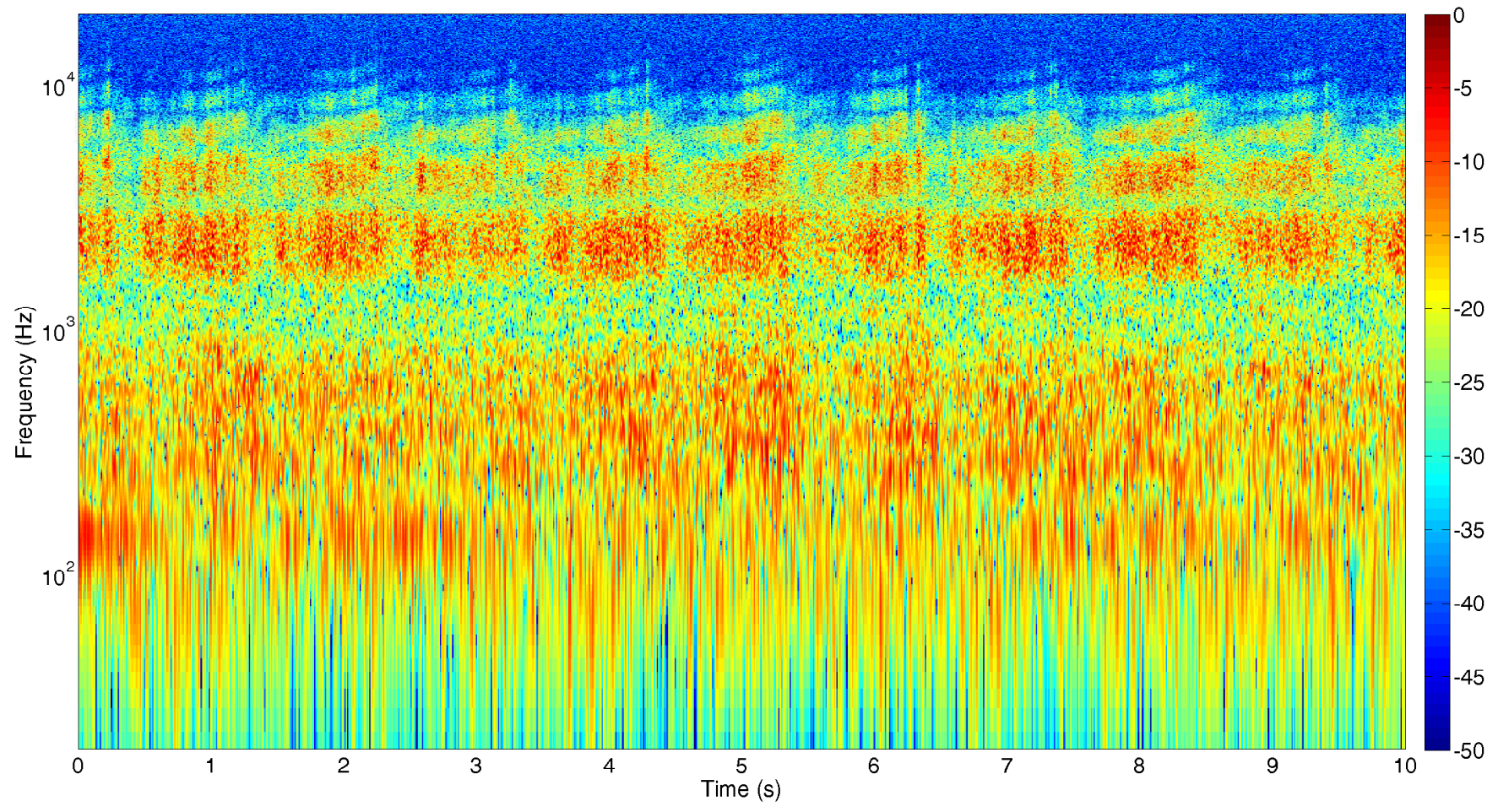




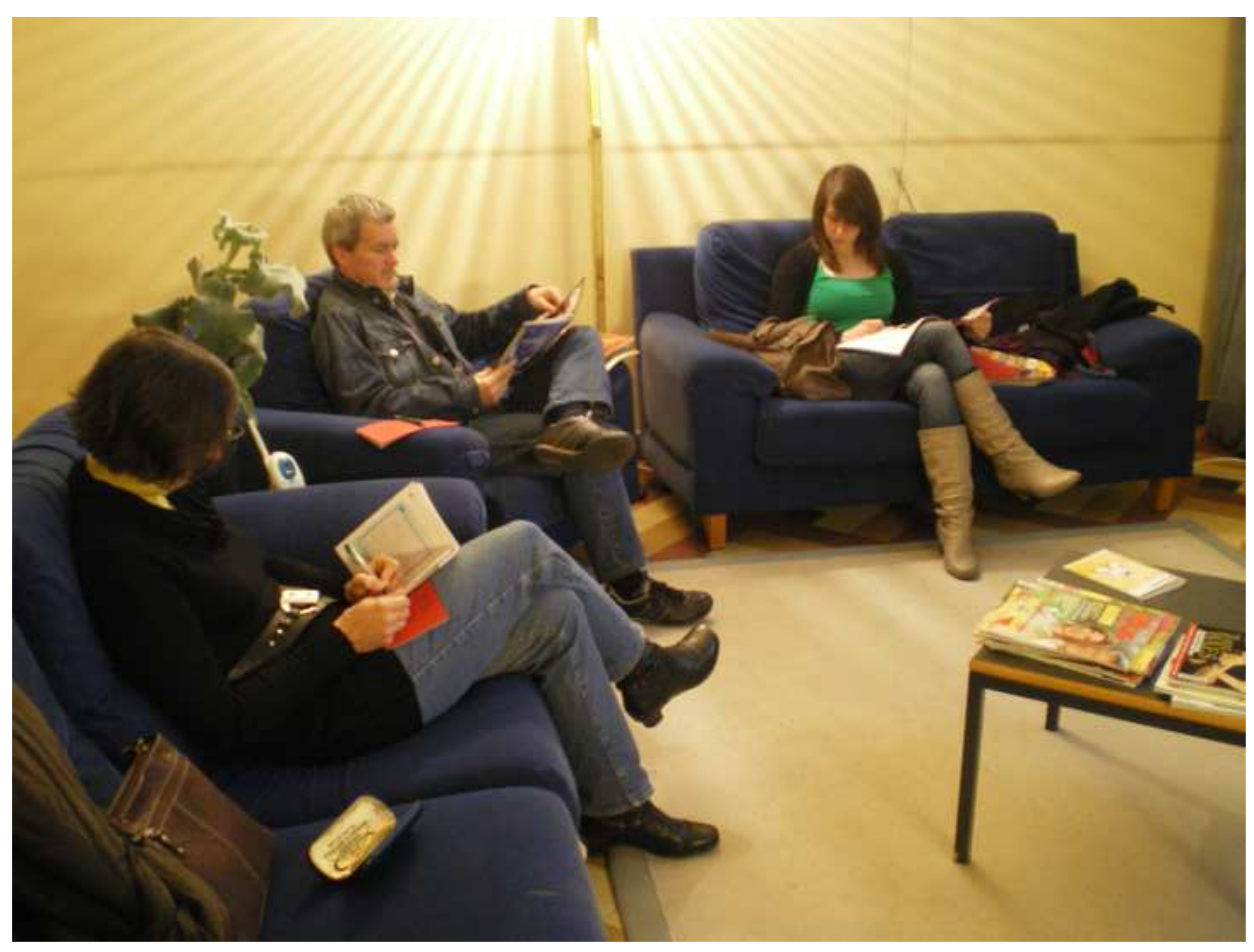




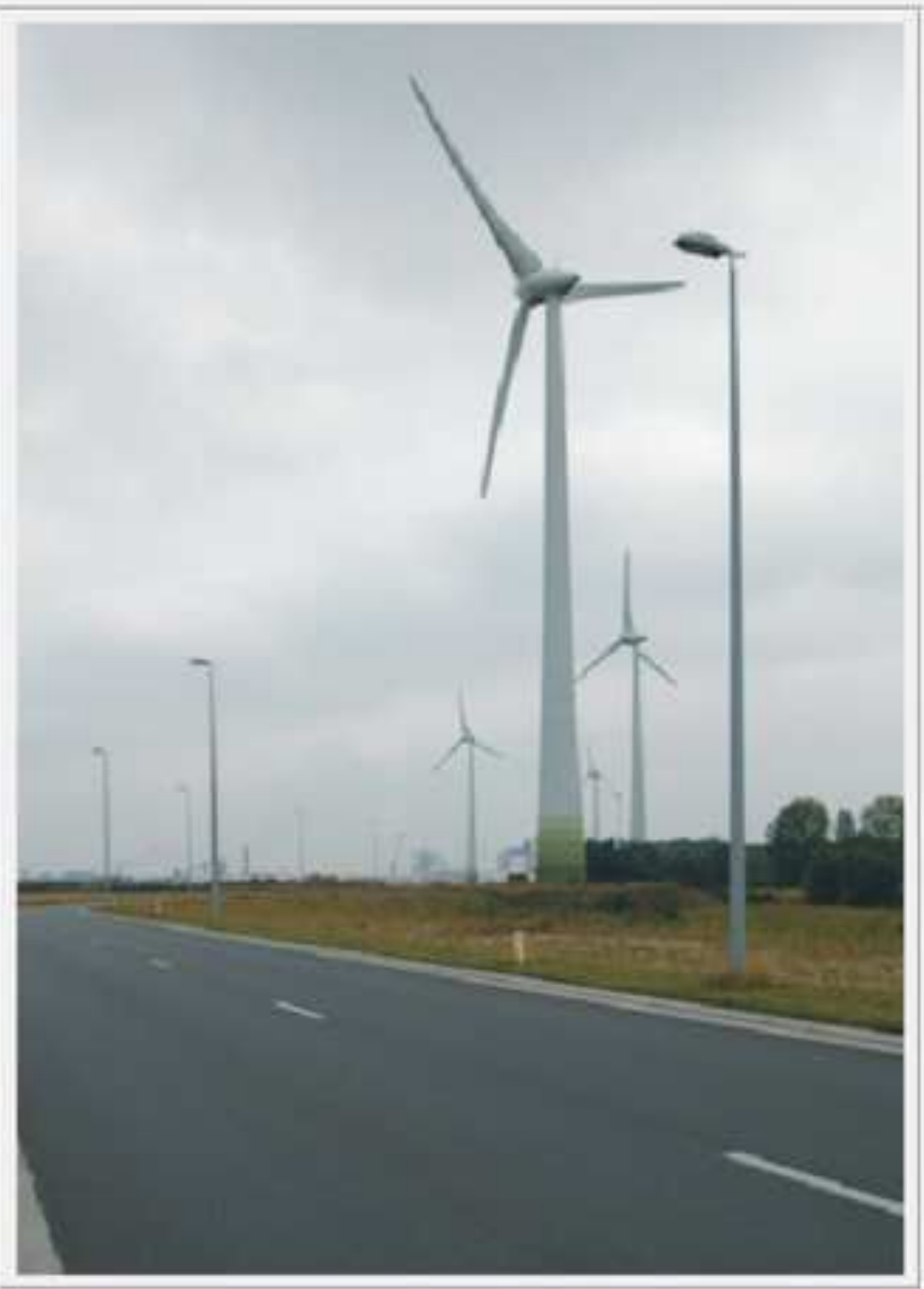

Luister naar beide geluidsfragmenten

Beluister fragment 1

\section{Beluister fragment 2}

Welke van deze twee geluidsfragmenten bevat volgens $u$ het windturbinegeluid? 

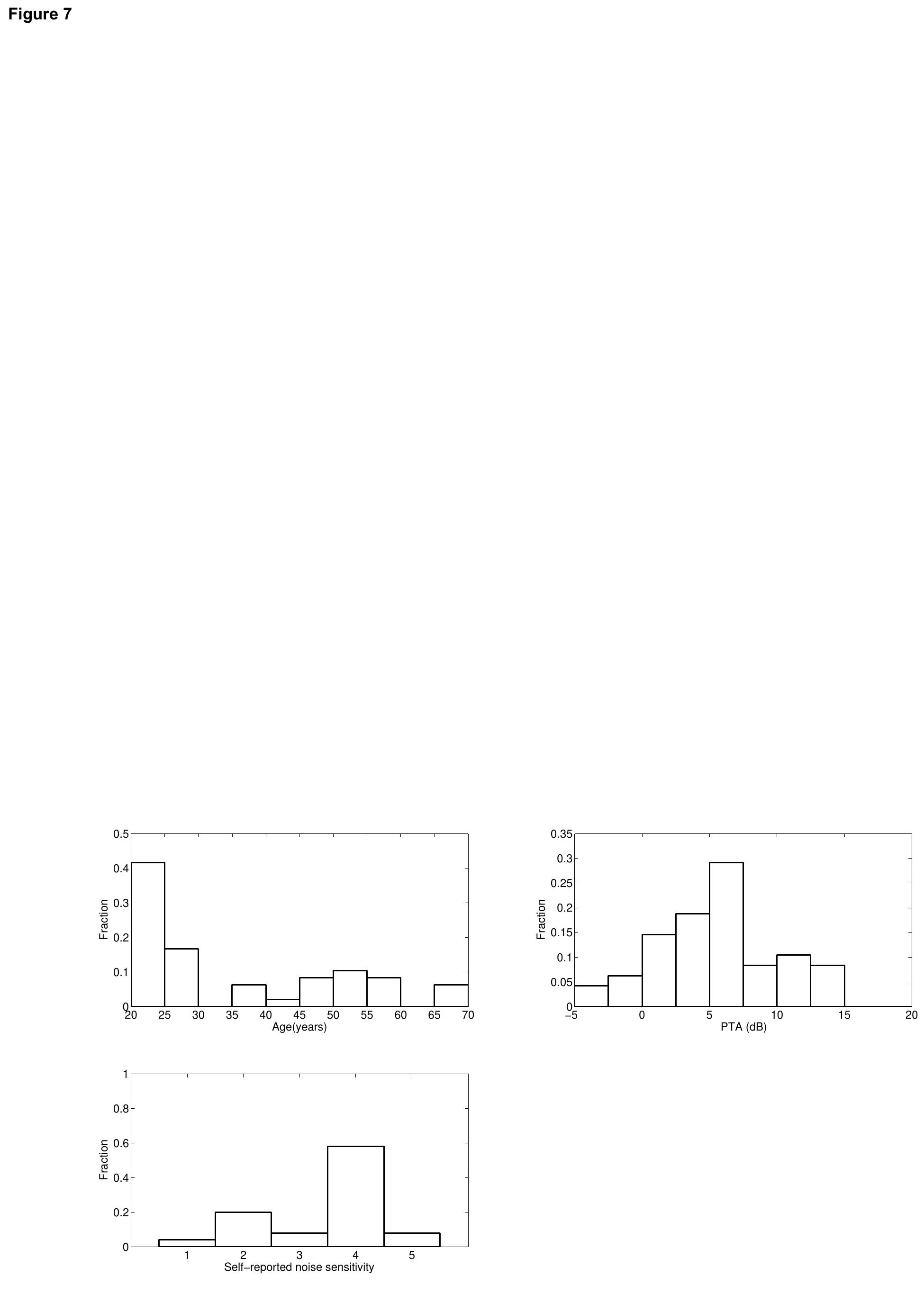

Figure 7

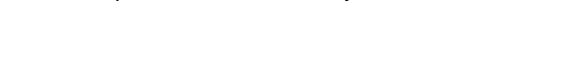

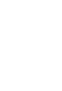

\section{Figure 7}

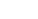
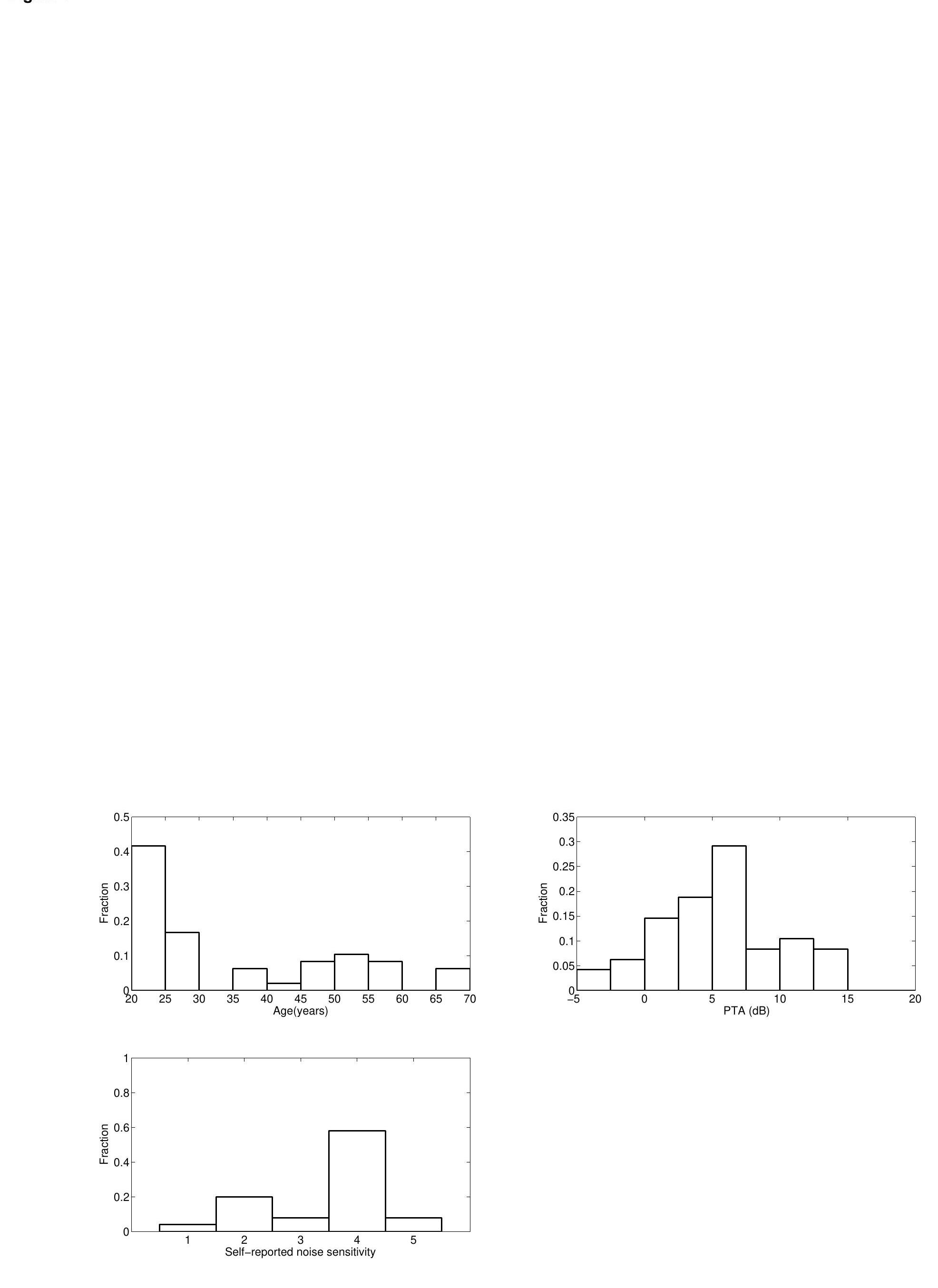


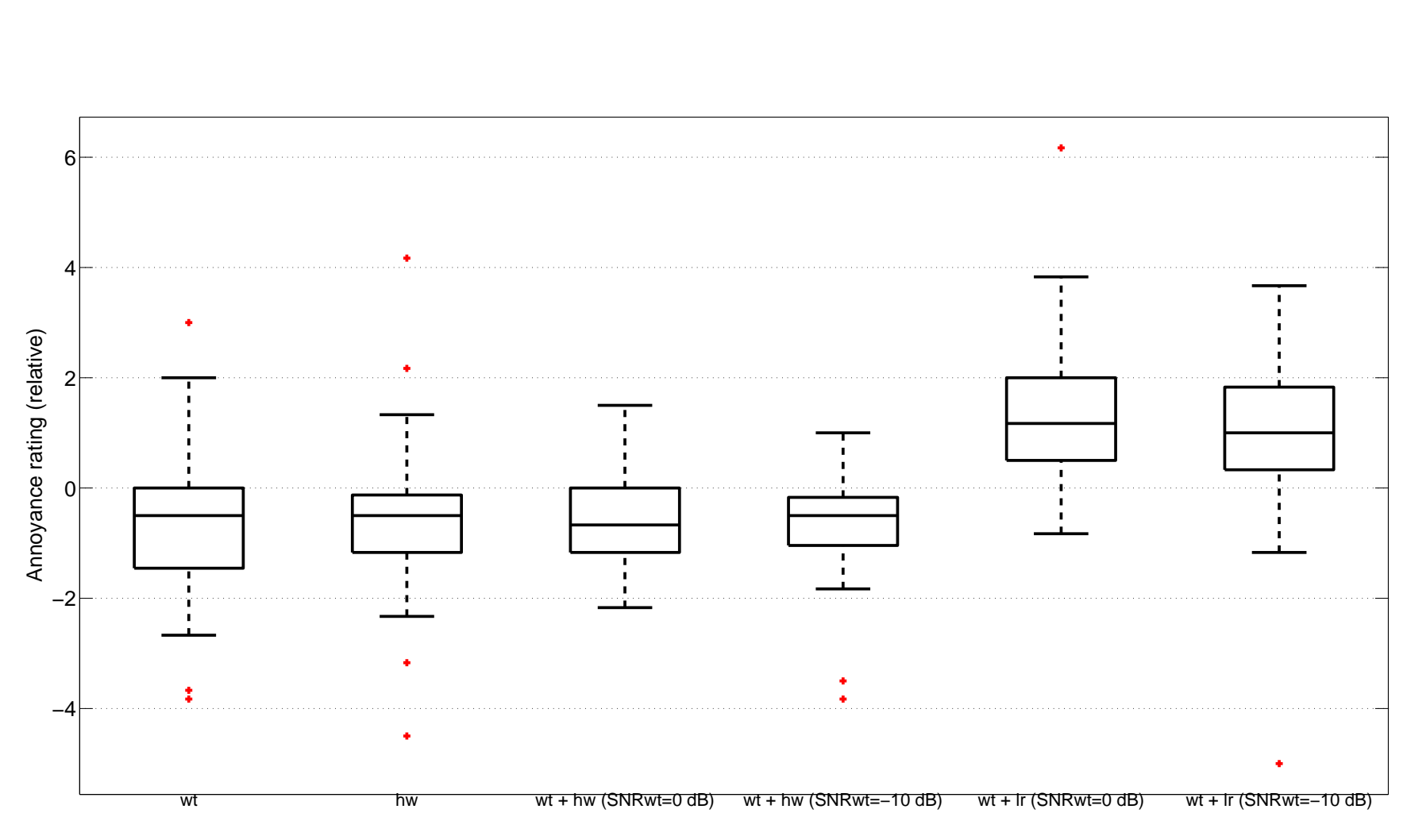

Figure 8

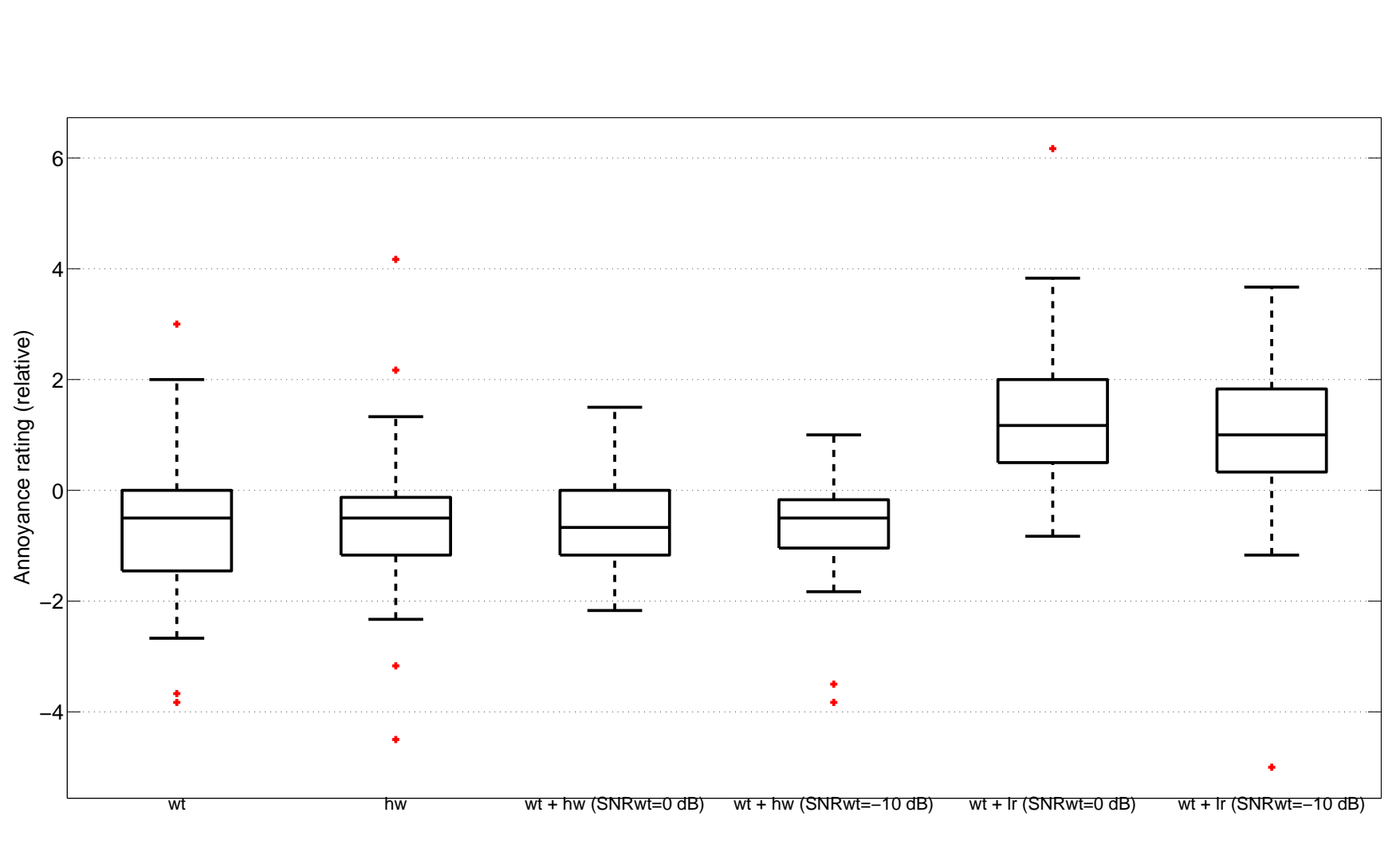

(

8
.

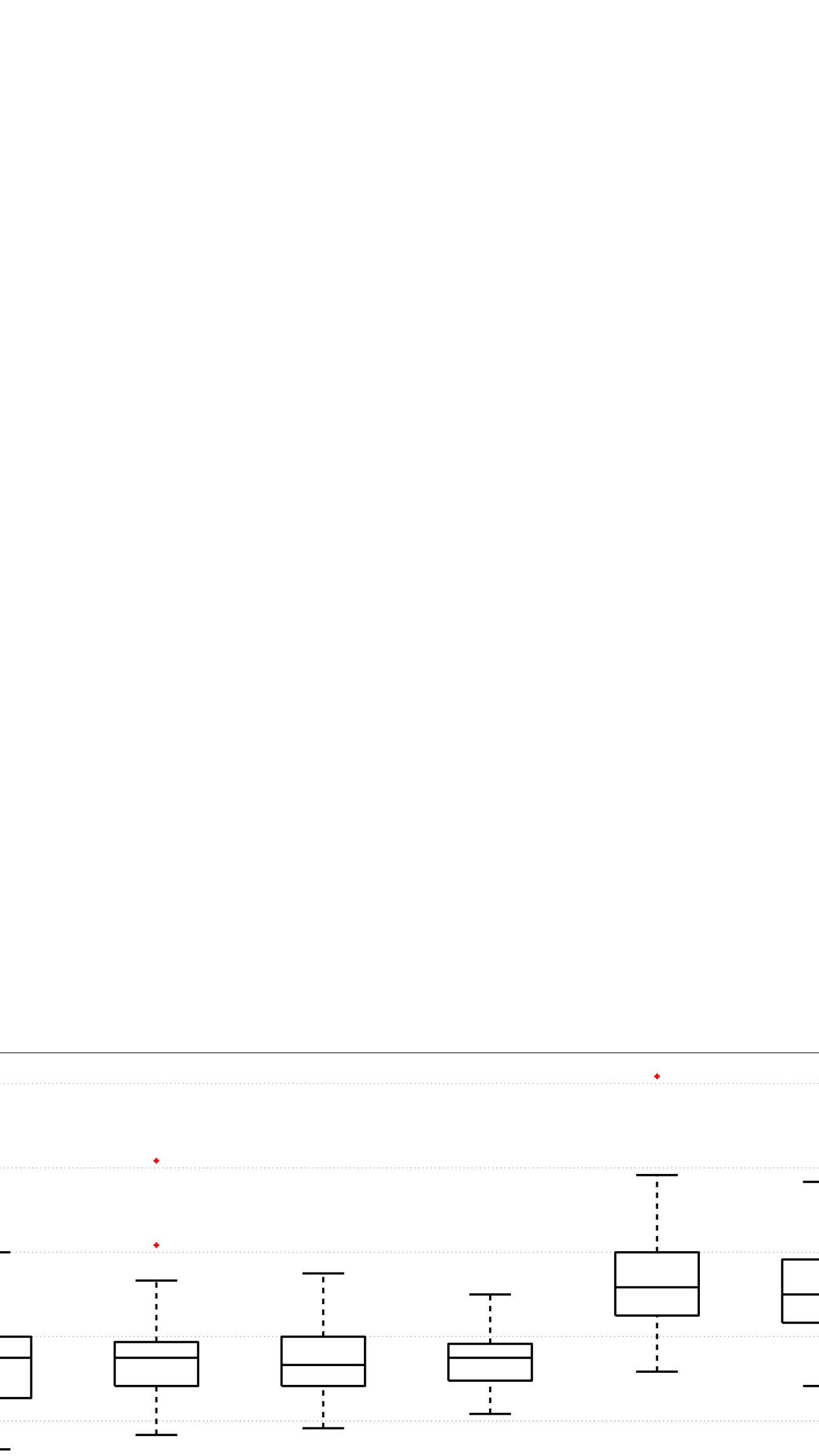




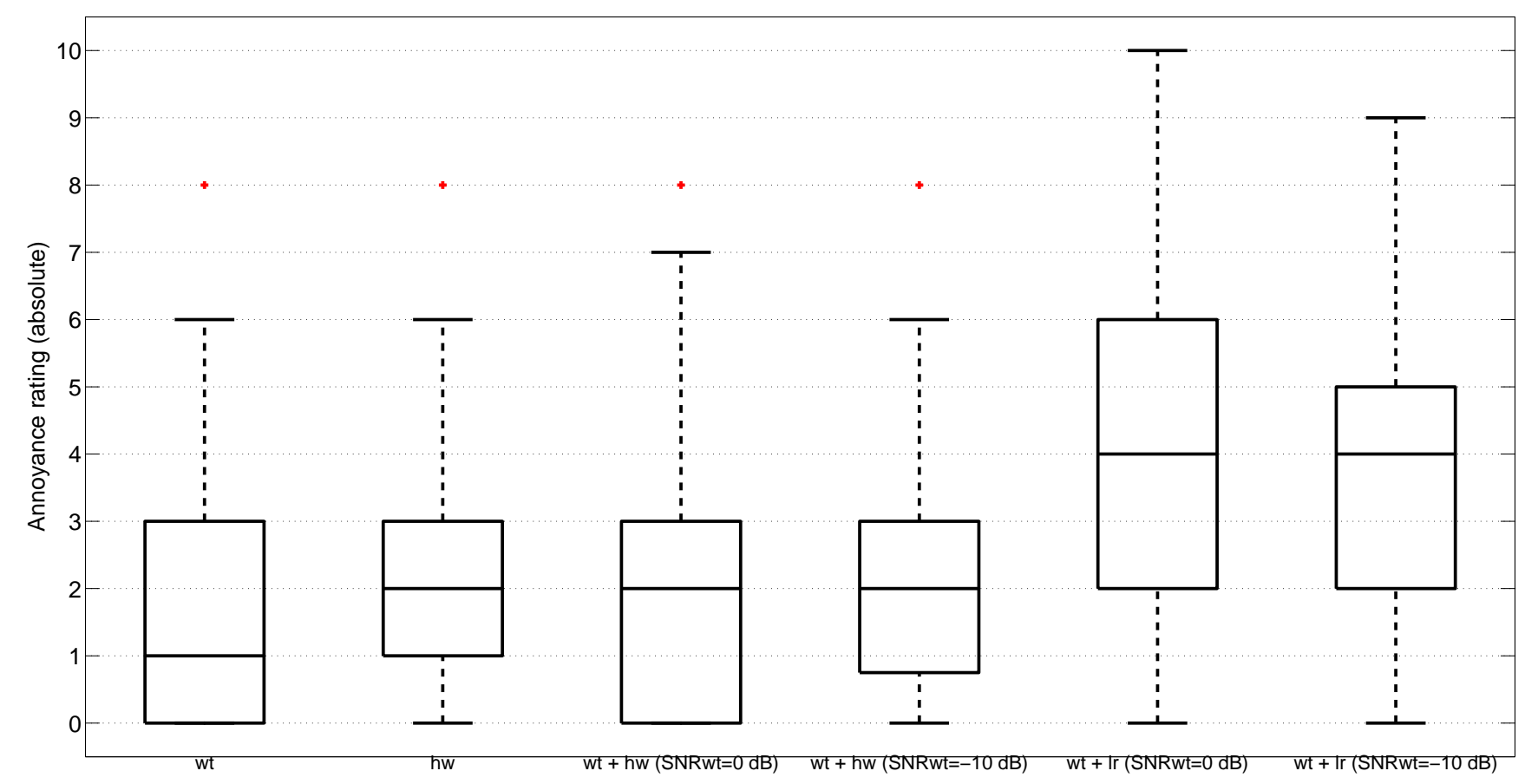

Figure 9

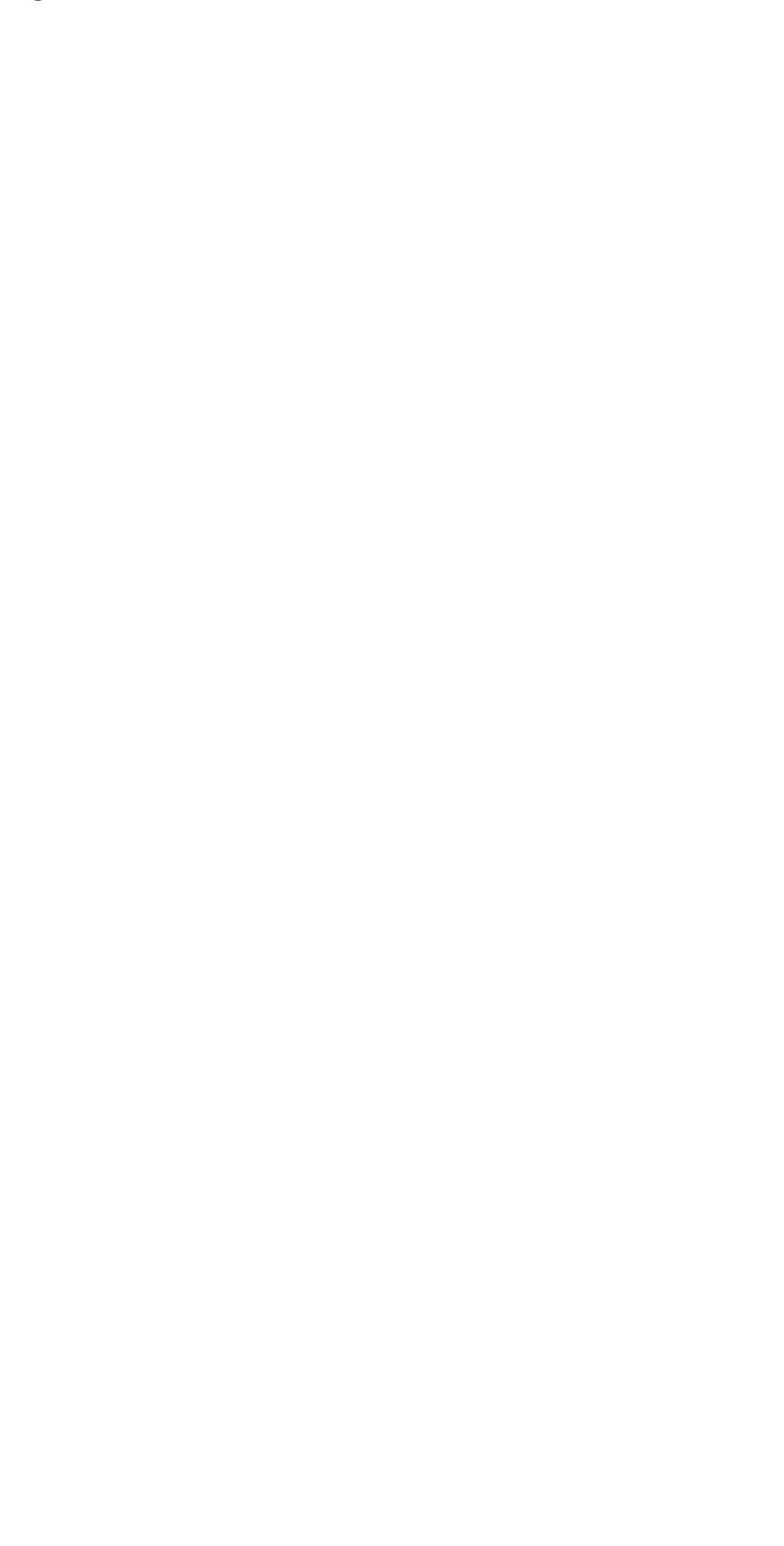


Figure 10

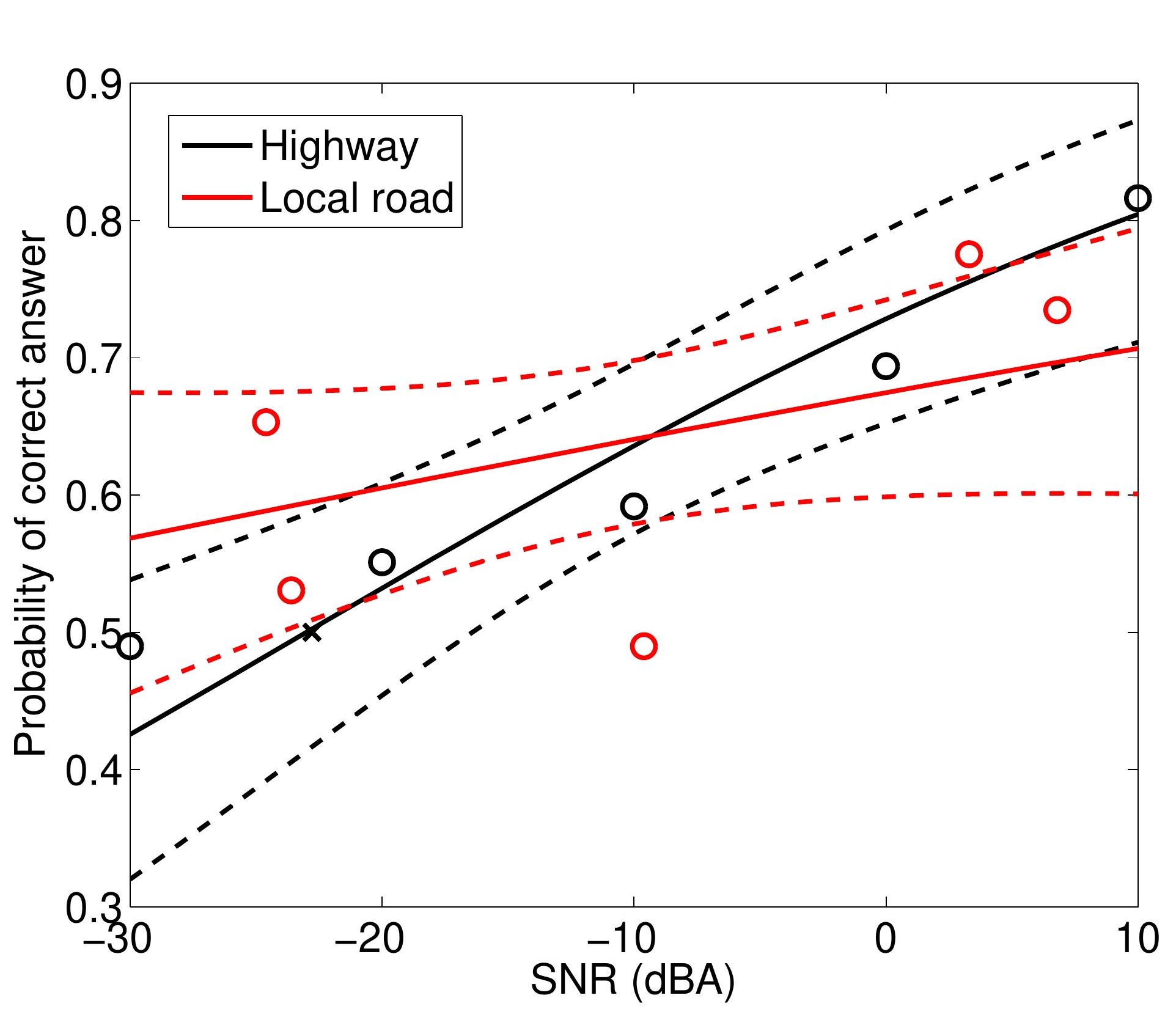

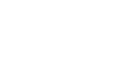

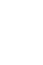
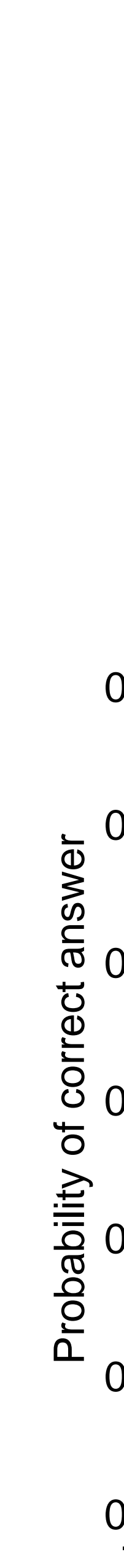
